\title{
From single molecules to life: microscopy at the nanoscale
}

\author{
Bartosz Turkowyd $^{1}$ - David Virant ${ }^{1} \cdot$ Ulrike Endesfelder $^{1}$
}

Received: 31 March 2016/Revised: 30 June 2016/Accepted: 7 July 2016/Published online: 9 September 2016

(C) The Author(s) 2016. This article is published with open access at Springerlink.com

\begin{abstract}
Super-resolution microscopy is the term commonly given to fluorescence microscopy techniques with resolutions that are not limited by the diffraction of light. Since their conception a little over a decade ago, these techniques have quickly become the method of choice for many biologists studying structures and processes of single cells at the nanoscale. In this review, we present the three main approaches used to tackle the diffraction barrier of $\sim 200 \mathrm{~nm}$ : stimulated-emission depletion (STED) microscopy, structured illumination microscopy (SIM), and single-molecule localization microscopy (SMLM). We first present a theoretical overview of the techniques and underlying physics, followed by a practical guide to all of the facets involved in designing a super-resolution experiment, including an approachable explanation of the photochemistry involved, labeling methods available, and sample preparation procedures. Finally, we highlight some of the most exciting recent applications of and developments in these techniques, and discuss the outlook for this field.
\end{abstract}

Keywords Super-resolution microscopy · Photophysics and photochemistry of fluorophores · Live cell imaging . Quantitative cell biology

Bartosz Turkowyd and David Virant contributed equally to this work.

Ulrike Endesfelder

ulrike.endesfelder@synmikro.mpi-marburg.mpg.de

1 Department of Systems and Synthetic Microbiology, Max Planck Institute for Terrestrial Microbiology and LOEWE Center for Synthetic Microbiology (SYNMIKRO), Karl-von-Frisch-Str. 16, 35043 Marburg, Germany

\section{Spatial and temporal scales in the life sciences and microscopy}

The timescales and spatial scales of the processes and molecules associated with life span extremely broad ranges, covering many orders of magnitude (Fig. 1). For instance, intracellular regulation (e.g., conformational changes or biochemical reactions within molecules) takes place at submillisecond timescales, nanosized molecules such as ATP (which serves the energy demands of cells) diffuse in milliseconds through cell volumes ranging from several micrometers up to millimeters, while (clustered) membrane receptors move at speeds that are about a magnitude slower. Large multicomponent machineries realize and control complex multilayered cellular functions that occur in seconds to hours. The ribosome, a large macromolecule which consists of two functional subunits of several dozen proteins on nucleic acid chain scaffolds, takes a matter of seconds to synthesize new peptide chains comprising hundreds of amino acids, which then quickly fold up into functional proteins. On the other hand, the replication of a full genome requires at least about 40 min for the 4.6 million nucleic acid base pairs of the bacterium Escherichia coli, and the cellular division cycle ranges from tens of minutes for $E$. coli to several hours for mammalian cells.

Observing and understanding all of these components of life requires us to be, at best, passive witnesses of undisturbed processes, but also to demand hard observational data that can allow us to quantitatively measure and trace all of the players involved - ranging from small molecules up to the interactions of whole cells in cellular communities - with the highest specificity and precision.

To achieve this, instrumentation is needed that permits a wide three-dimensional view but also allows details to be 
Fig. 1a-b Spatial and temporal scales in the life sciences and microscopy. a Selected characteristic submicrometer objects are separated on the basis of biological (above the axis, green) and technical (below the axis, blue) significance. The IgG antibody structure $(15 \mathrm{~nm})$ contains two other notable structures: the antigen-binding region, called the Fab fragment $(10 \mathrm{~nm}$, blue $)$ and the singlevariable domain ( $3 \mathrm{~nm}$, red), from which so-called nanobodies from cameloids are derived. Structures are taken from the PDB [GFP $1 \mathrm{KYS}$, IgG 1IGT, SNAP $3 \mathrm{KZZ}$, DNA 4LEY] and PubChem [ATP CID 5957, Alexa Fluor 647 CID 102227060]. b Timescales of various important biological processes (above the axis, green) and physical events, as well as typical timescales associated with microscopy procedures (below the axis, blue)

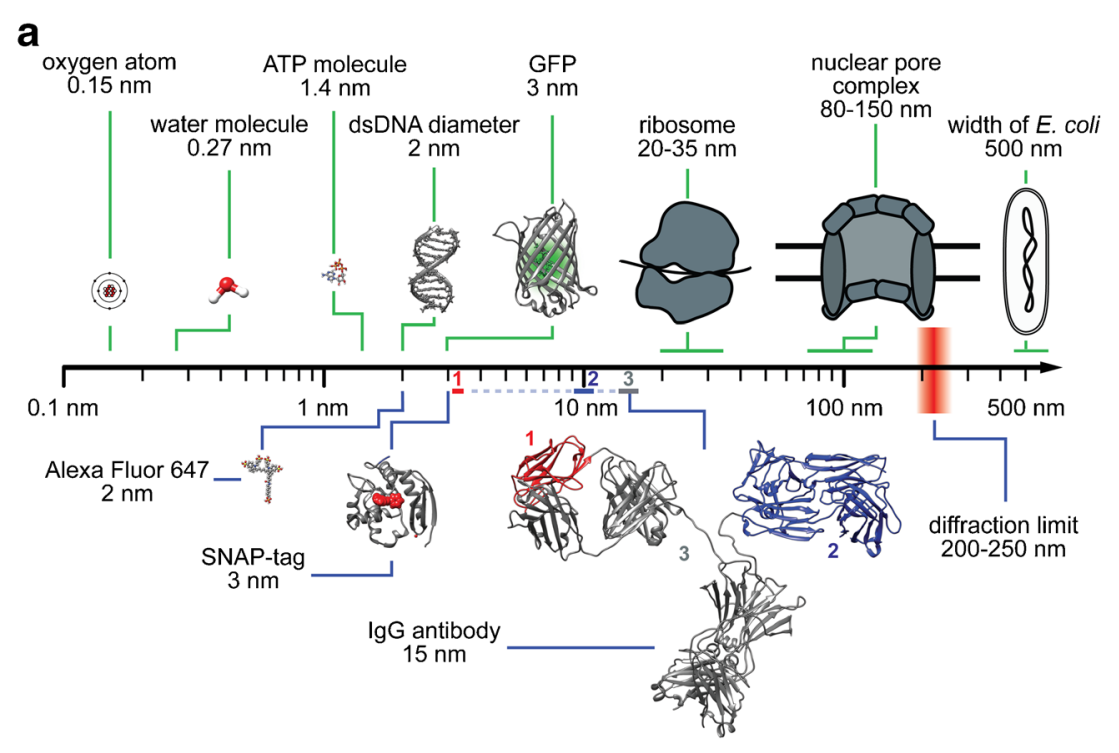

b

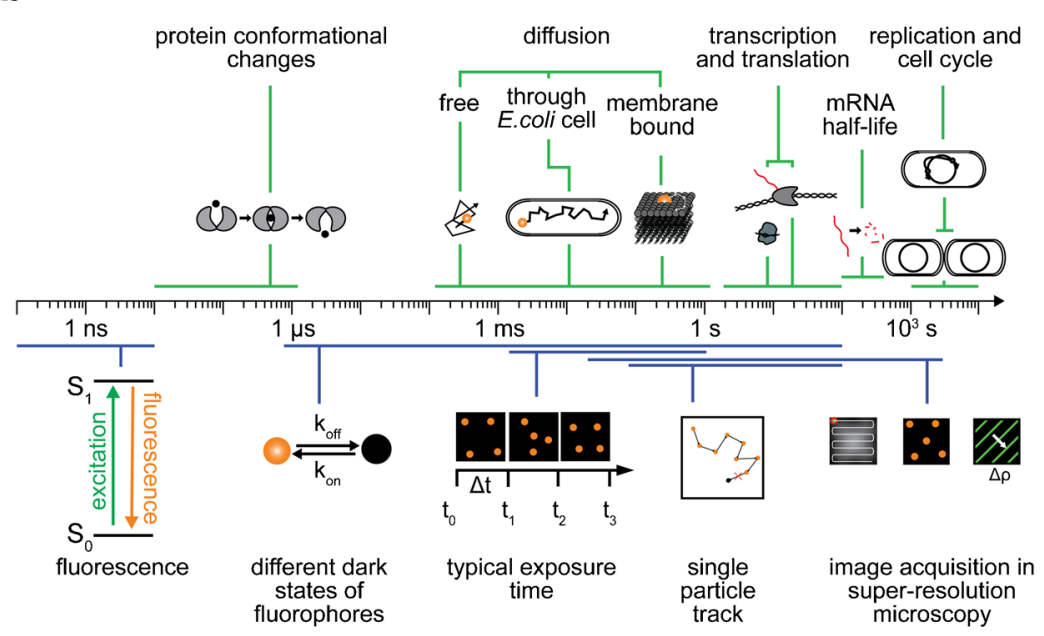

explored in high resolution, is noninvasive but can tell different cellular components apart, and offers detection that is rapid enough to be able to probe the processes of interest.

Today, the use of modern super-resolution fluorescence microscopes allows us to zoom into the intracellular structures of live cells [1,2]. It is not only possible to resolve specimens in greater detail than naturally possible using the discriminating power of the human eye through the application of conventional light microscopes, but we are also able to circumvent the diffraction limit of light and study structures at nearmolecular scale. This significant gain in resolution (which has revealed the heterogeneous nature of the lives of single cells), the inherent specific contrast of single fluorescent labels, and the ability to live-cell image single cells and large multicellular organisms have made fluorescence super-resolution microscopy one of the most powerful tools applied in the life sciences.

Nevertheless, there are limitations: the maximal photon flux of a fluorophore - which is mainly determined by its fluorescence lifetime-yields a lower bound for the detection range when observing molecular dynamics, and its maximum photon budget (above which it is irreversibly destroyed, i.e., photobleached) marks the upper bound for studying individual molecules. Technology-wise, minimal exposure times in the millisecond range limit the maximum observation rate of a planar live image array [3], and (for example) the sizes of labeling molecules such as dyes, protein tags, and antibodies yield steric resolution limits [4, 5]. Typical sizes of labeling molecules and the range of timescales of various life processes and imaging procedures are visualized in the lower panels of Fig. $1 \mathrm{a}$ and $\mathrm{b}$.

It is important to point out that none of the advanced super-resolution microscopy techniques are routine methods as yet. They work close to current technological limits, and thus improve with each new implementation. Behind their stunning results and attractive images hide highly complex and tailored experimental designs. It is thus advisable to define the particular biological question 
to be answered as precisely as possible, and to plan biological experiments such that they suit the techniques well. Therefore, here, we will briefly review the basic principles of the three most widely used super-resolution microscopy techniques: stimulated-emission depletion (STED) microscopy [6], structured illumination microscopy (SIM) [7], and single-molecule localization microscopy (SMLM) [8-10], as depicted in Fig. 2 and summarized in Table 1. We explain, in detail, the essential characteristics of currently used reporter fluorophores, from their individual photophysics to general labeling strategies. Finally, we highlight the recent advances of the last few years, which have not only allowed the molecular compositions and structures of individual cellular components to be elucidated, but have also enabled us to place them into their native environmental context of large-scale spatial organization and to follow their dynamics. At the end of the paper, we emphasize the main challenges we currently face in order to achieve further improvements in these techniques and we introduce promising correlative schemes and sophisticated algorithmic and analytic tools which facilitate large-data and computational systems biology approaches.

\section{Principles of super-resolution microscopy}

The resolution of light microscopy is often introduced via the Rayleigh criterion. Light from point-like sources is convolved by the so-called point-spread function (PSF) of an optical system when transmitted through a diffraction-limited microscope (Fig. 2a). In 1896, Lord Rayleigh defined the maximum resolution of an optical system as the minimum distance between two point-like objects which can be separated as individual sources. He regarded two point sources of equal strength as just discernible when the main diffraction maximum of one image coincides with the first minimum of the other. For an epifluorescence microscope with a circular aperture where the light is collected with the same objective, this yields

$d=\frac{0.61 \lambda}{\mathrm{NA}}$,

where $\lambda$ is the wavelength of light and NA is the numerical aperture [16].

Nevertheless, as already demonstrated by Zsigmondy using his ultramicroscope in 1902 [17], particles with dimensions below the resolution limit of visible light can be resolved. Also, confocal or multiphoton fluorescence approaches possess higher resolution than epifluorescence microscopes, as these techniques repress out-of-focus fluorescence, permitting straightforward three- dimensional imaging [18]. The resolution of near-field scanning microscopy (NSOM) is not limited by diffraction, as the diffraction limit applies only to light that has propagated a distance that is sufficiently larger than its wavelength. NSOM is therefore only limited by the aperture of the nanometer-sized excitation and detection tip placed near the sample [19].

Since the development of STED, the first far-field super-resolution fluorescence microscopy technique, many new methods that spatially or temporally confine fluorescence (which allows them to circumvent the diffraction barrier) have evolved. They can be categorized into two types of super-resolved far-field methods, with the first group concentrating on particular incident excitation light patterns and the second focusing on the modulation of the detected emission light over time. To be more specific, the first group, including techniques such as STED and SIM, make use of structured illumination schemes which spatially modulate the fluorescence of molecules such that not all of them simultaneously emit light. The second group, namely SMLM, rely on single-molecule imaging, and uses stochastic photomodulation of individual fluorophores. The number of photoswitchable fluorophores in their active fluorescent state can be controlled by irradiating the fluorophores with specific wavelengths of light. Thus, the stochastic activation of fluorescence at low rates allows the fluorescence emissions of single fluorophores to be spatially and temporally separated.

\section{Stimulated-emission depletion microscopy}

In STED microscopy [6], the sample is scanned by a subdiffraction excitation spot. This spot is realized by superimposing two lasers: an excitation laser with a focused beam waist limited by diffraction and a STED depletion laser in a donut-shaped mode (achieved by phase modulation) with a wavelength at the far end of the fluorescence spectrum of the fluorophore used (Fig. 2bi). As a consequence, all of the fluorophores in the focal spot of the excitation laser are excited, whereas those located within the area of the donut-shaped STED laser are again quickly depleted from the excited state and forced back to their ground state by stimulated emission, resulting in the release of a photon identical to the incident STED depletion photon. This process only leaves fluorophores at the subdiffraction-sized central spot in the excited state, and their spontaneous fluorescence emission is measured. By precisely scanning the entire sample and measuring the respective fluorescence intensity of each subdiffraction area (Fig. 2bi, bottom), then, without the need for any further post-processing steps (Fig. 2bii), an image is reconstructed (Fig. 2biii). 
a

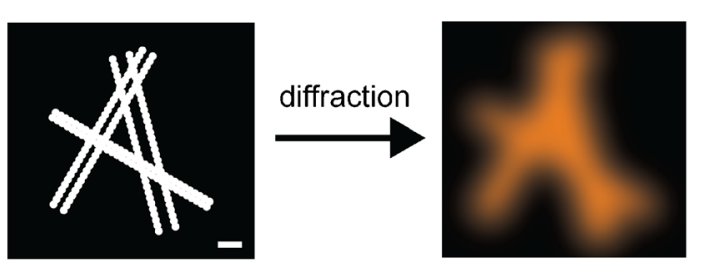

b
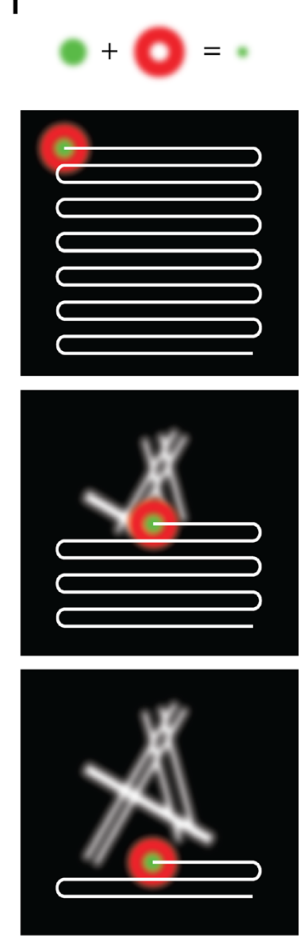

ii
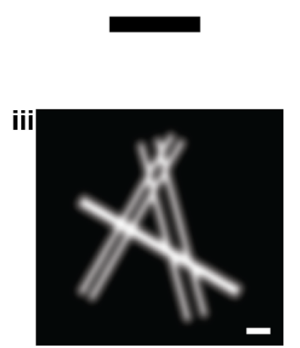

C

i
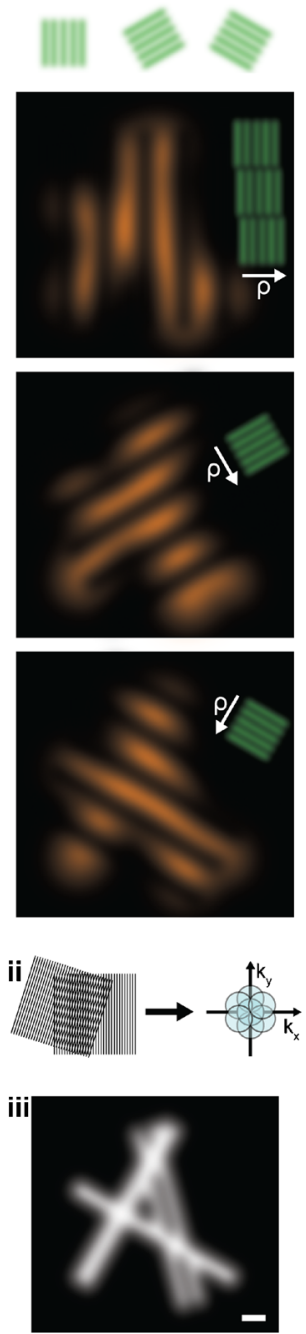

d

SMLM

i
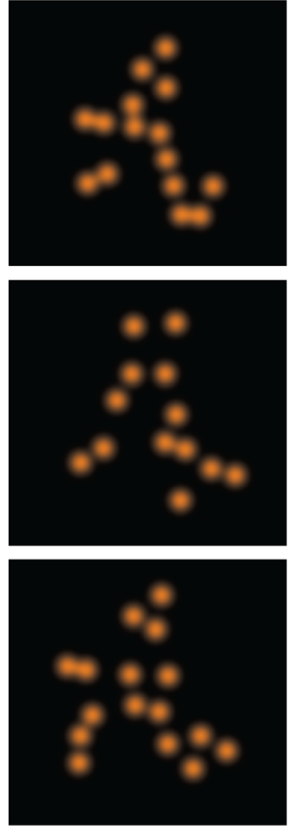

ii
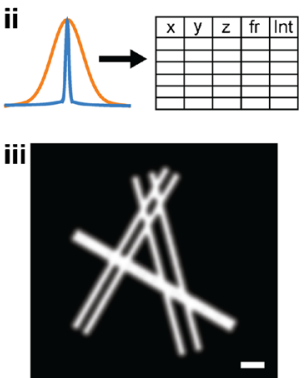

Fig. 2a-d Principles of super-resolution microscopy techniques. a Left: Scheme of six filaments decorated with fluorophores (represented by large icons for visibility) and grouped into three pairs at simulated distances of 50, 100, and $150 \mathrm{~nm}$; scale $200 \mathrm{~nm}$. Right: A typical image of this structure obtained by conventional fluorescence microscopy is limited by the diffraction of light. $\mathbf{b} i$, top: For STED, the structure is scanned by a subdiffraction excitation spot obtained by combining an excitation laser (green) with a, by phase-modulation shaped, depletion laser (red). After scanning the entire structure ( $i$, bottom), and without performing any further post-processing steps (ii), an image is reconstructed (iii). $\mathbf{c}$ In SIM, fluorophores are excited by a series of regularly spaced illumination patterns of known frequency, orientation, and phase which modulate the fluorophore emissions. This results in visible low-frequency Moiré patterns that are dependent on the structure imaged $(i)$. By analyzing the images for their spatial frequencies, an enlarged frequency space is obtained (ii), and a subdiffraction image is reconstructed (iii). d In SMLM, the fluorescence is modulated by photoswitching between "off" and "on" states. Most of the fluorophores are forced to reside in a dark off state; only a small subset of spatially separated fluorophores in the on state is allowed to emit fluorescence at a given time. After sequentially imaging thousands of subsets of fluorophores $(i)$, the nanometer-precise fluorophore positions can be extracted from the diffraction-limited individual emissions (ii), and an image is reconstructed (iii). The three superresolved images labeled (iii) visualize typical resolutions obtained by the methods: on the order of $50 \mathrm{~nm}$ (STED), $100 \mathrm{~nm}$ (SIM), and $20 \mathrm{~nm}$ (SMLM); scale $200 \mathrm{~nm}$ 
Table 1 Overview of the characteristics of various super-resolution microscopy techniques

\begin{tabular}{|c|c|c|c|c|}
\hline & STED & Linear SIM & Nonlinear SIM & SMLM \\
\hline Microscope type & Laser scanning & Widefield & Widefield & Widefield \\
\hline xy resolution (nm) & $20-70$ & $80-100$ & $\sim 45$ & $10-40$ \\
\hline $\mathrm{z}$ resolution $(\mathrm{nm})$ & $30-100$ & $\sim 300$ & $\sim 170$ & $10-50$ \\
\hline Temporal resolution & $\mathrm{ms}$ to $\mathrm{s}$ & $\mathrm{ms}$ to $\mathrm{s}$ & $\mathrm{ms}$ to $\mathrm{s}$ & $\mathrm{s}$ to $\min$ \\
\hline Laser intensities $\left[\mathrm{W} / \mathrm{cm}^{2}\right]$ & $\sim 10^{4}-10^{9}$ & $\sim 10-10^{2}$ & $\sim 10^{2}-10^{6}$ & $\sim 10^{3}-10^{4}$ \\
\hline Suitable fluorophores & $\begin{array}{l}\text { Photostable } \\
\text { fluorophores }\end{array}$ & $\begin{array}{l}\text { All common } \\
\text { fluorophores }\end{array}$ & $\begin{array}{l}\text { Photostable or photoswitchable } \\
\text { fluorophores }\end{array}$ & $\begin{array}{l}\text { Photoswitchable } \\
\text { fluorophores }\end{array}$ \\
\hline Number of colors & 3 & 3 & 1 & 4 \\
\hline Photobleaching & Moderate to high & Low to moderate & Moderate to high & $\begin{array}{l}\text { Low to moderate } \\
\text { (reversible switching) } \\
\text { High } \\
\text { (irreversible switching) }\end{array}$ \\
\hline
\end{tabular}

Values are taken from $[10-15]$

The size of this effective subdiffraction scanning beam can be varied depending on the intensity of the STED depletion beam. The resulting resolution of STED microscopy can be described by

$d_{\mathrm{STED}}=\frac{d}{\sqrt{1+I / I_{\mathrm{S}}}}$,

where $d$ is the conventional resolution limit as defined by the Rayleigh criterion, $I$ is the intensity of the STED depletion laser, and $I_{\mathrm{s}}$ is the effective saturation intensity, which can be defined as the intensity at which the probability of fluorescence emission is reduced by half [20].

By choosing the wavelength of the STED depletion laser to be at the far end of the fluorophore's spectrum, reabsorption from the ground state as well as further absorption processes from the excited state can be neglected. Further, the resulting stimulated photons identical to the STED depletion wavelength possess a longer wavelength than the majority of photons obtained by spontaneous fluorescence emission. They can therefore be easily spectrally filtered, and-as stimulated emission also occurs on faster timescales-filtered temporally too. As it is a confocal technique, STED microscopy naturally permits optical sectioning, but three-dimensional imaging schemes have been further improved by, for example, creating an isotropic focal scanning spot using two opposing objectives [21].

The sample is scanned in steps as small as the effective subdiffraction-sized excitation spot, but is irradiated by the much larger, diffraction-limited, foci of the excitation and STED depletion lasers. Thus, the fluorophores are subjected to multiple excitation and de-excitation steps under high STED laser intensities, which requires them to be extraordinarily photostable. STED microscopy was initially realized in a pulsed laser scheme [6]; continuouswave illumination STED microscopy was implemented later [22]. However, rather high intensities are required in both imaging schemes, leading to increased photobleaching and phototoxicity in the sample. This negative effect can be reduced by employing sophisticated imaging modes which lower or shorten the applied laser intensities, e.g., by time gating [23], by selective, feedbacked use of the depletion beam to reduce the number of state transition cycles [24], or by replacing (a concept also termed RESOLFT: reversible saturable optical (fluorescence) transition) [25] or assisting [26] the stimulated depletion mechanism with an on-off photoswitch. STED utilizing moderate laser power schemes can be applied to the imaging of live cells as well as living tissue and living organisms (for a detailed review, see [27]).

For multicolor STED microscopy, either a pair of lasers is required for each fluorophore [28], or, for spectrally close fluorescence spectra, only one depletion laser is needed [29]. This further automatically coaligns the effective scanning spots of both colors. Very specific fluorophore pairs, chosen to be suitable for spectral demixing approaches or to demonstrate reverse photochromic behavior, can be operated by just one pair of lasers $[30,31]$.

\section{Structured illumination microscopy}

SIM uses regularly spaced patterns of known spatial frequency, orientation, and phase to illuminate the sample by a 
structured excitation light series ([7]; detailed review [32]). This leads to modulated fluorescence emissions which form defined interference Moiré fringes of high and low frequencies, as the light emitted from a specific point in the sample is the product of the local structure of the sample (more precisely the spatial distribution of the fluorophores) and the local excitation intensity. As the corresponding fluorescence image seen through the microscope is diffraction limited and thus convolved with the PSF of the optical system, only the lowfrequency Moiré patterns can be measured. These structurespecific patterns are registered for different sequential phases and orientations of the illumination pattern to sample the maximum isotropic frequency space (Fig. 2ci). By measuring the apparent Moiré fringes and knowing the properties of the chosen illumination patterns, it is possible to retrieve information at higher spatial frequencies than normally possible in a widefield microscope (Fig. 2cii): the diffraction limit can be described as a circular boundary in the transmitted frequency space with a maximal frequency of $k_{\max }$, equaling $1 / d$. Thus, only the spatial frequencies with $k \ll k_{\max }$ pass through the optical system. Using structured illumination, which allows the detection of low-frequency Moiré interference patterns, spatial information about the sample from higher frequency bands is shifted into detectable lower frequency bands. All of the acquired images can be analyzed for their spatial frequencies and then be unmixed by their multiple overlapping components in frequency space. This allows the high frequencies obtained using the Moiré information to be shifted back to their original frequencies. The resulting enlarged frequency space encompasses about $2 k_{\max }$, as the low-frequency Moiré patterns must remain visible above the diffraction limit. Using an inverse Fourier transform back into image space, a superresolved SIM image showing a linear twofold increase in resolution can then be reconstructed (Fig. 2ciii).

Ignoring for a brief moment the rather complex postprocessing of the raw data acquired by sophisticated SIM software (recently published open-source options are [33, 34]), SIM is the most straightforward approach in the field of super-resolution microscopy: the technique is based on standard widefield fluorescence microscopes, only requires (in the simplest version of SIM) a movable grating placed in a Fourier plane of the illumination path, and works for all common (albeit best for bright) fluorophores. SIM can be used to image live cells $[11,35]$ and has been extended to three-dimensional SIM [12], is capable of imaging live organisms [36], and allows for multicolor imaging [37]. Nevertheless, common artifacts (arising from imperfect imaging or algorithms) should be carefully considered, avoided, or corrected for: stripes in a reconstituted SIM image emerge from photobleaching, sample drift, or setup vibrations, a low fluorescence modulation contrast results in noise in the high-frequency range, and spherical aberration as well as refractive index mismatching creates halos or the doubling of features [38].
A higher resolution than that obtained by linear SIM is achieved by nonlinear SIM, which is realized by either saturating the fluorescence through the application of strong illumination intensities [39] or by using photoswitchable fluorophores [13, 40] (similar to RESOLFT [25]) to create illumination patterns that include higher harmonic frequencies. However, the increased resolution of this technique comes at the expense of a limited choice of fluorophores, which need to be either highly photostable (in order to withstand the strong illumination intensities) or photoswitchable. The resolution obtained using SIM approaches can be determined via

$d_{S I M} \approx \frac{d}{2+h}$,

where $d$ is the conventional resolution limit and $h$ is the number of higher harmonics achieved when applying nonlinear SIM schemes $[13,39,40]$. For linear SIM, $h$ equals zero, so the resolution enhancement is about twofold.

\section{Single-molecule localization microscopy}

Single-molecule localization-based techniques such as photoactivated localization microscopy (PALM) ([8], (direct) stochastic optical reconstruction microscopy $((d)$ STORM) $[9,10]$, ground-state depletion followed by individual molecule return (GSDIM) [41], and many other related techniques [42] are commonly grouped together under the term "single-molecule localization microscopy" (SMLM). They all require tight control over the photoswitching of individual fluorophores, as discussed in detail in this review, and they rely on the use of postprocessing algorithms to generate the super-resolved data (see the review by Small and Stahlheber [43] and comparative studies of localization algorithms [44] and singleparticle tracking algorithms [45]; most of the relevant algorithms are openly available).

In SMLM, the main principle is stochastic photoswitching and the detection of single spatially separated fluorophores. To achieve this, all fluorophores are modulated by photoswitching them between "off" and "on" states. Most of the fluorophores are forced to reside in a long-lasting dark off-state; only a small subset of fluorophores in the on state are allowed to emit fluorescence at a given time. By sequentially imaging typically several thousand subsets of spatially distinguishable fluorophores, all of the emitters are detected over time (Fig. 2di). The photons emitted from the fluorophores are distributed in diffraction-limited spots and registered in a stack of time-resolved images until all of the fluorophores have been read out. The spots can be identified by imageprocessing algorithms, allowing the positions of the 
fluorophores and other properties (fluorescence intensity, duration of fluorescence, precision of the positioning fit, etc.) to be precisely determined and then stored in a large table (Fig. 2dii). Using the fluorophore centroids, a superresolved image is reconstructed (Fig. 2diii).

The resolution limit of SMLM is mainly determined by the precision with which individual fluorophores are localized, which can be simplified to

$d_{\mathrm{SMLM}} \approx \frac{d}{\sqrt{\mathrm{N}}}$,

where $d$ is the conventional resolution limit and $N$ is the number of photons detected in a single fluorescence spot [46].

SMLM approaches are more sensitive to background signals than both of the previously described methods, as SMLM determines the positions of individual molecules to a high precision based on their individual fluorescence levels. To assign as many photons as possible to a single fluorophore, it is highly desirable to achieve the best possible signal-tonoise ratio. For thin (mainly two-dimensional) samples, effective background noise reduction can be achieved using total internal reflection fluorescence microscopy (TIRF), where the incident laser light is totally internally reflected at the glasswater boundary between the coverslip and sample [47]. In this illumination scheme, only the fluorophores in a very thin layer within the exponentially decaying evanescent field above the coverslip can fluoresce. Thus, a large fraction of the usual background signal caused by autofluorescence or by the scattering of the laser light and originating from the whole sample volume is suppressed. Another approach is to illuminate the sample in a highly inclined and laminated optical sheet (HILO) [48]. In this mode, the excitation laser light leaves the objective at a very narrow angle, which results in an inclined beam passing through the sample. This illumination in the form of an optical light sheet is then almost perpendicular to the detection path of the microscope.

To allow for three-dimensional SMLM imaging, several optical methods have been utilized to encode the third dimension: astigmatic PSF shaping by a cylindrical lens, biplane alignment, a dual-objective scheme allowing for the interference of the signal, and several further phase modulations have been developed that (for example) create a double-helically arranged PSF or a self-bending PSF which spans a large field of view at isotropic resolution [1]. These three-dimensional SMLM read-out schemes can be combined with spatially confined activation approaches based on temporal focusing [49], selective plane illumination microscopy [50], or lattice light sheet illumination [51].

SMLM allows for multicolor imaging if the photoswitching mechanisms of the fluorophores used fit together well; i.e., when they tolerate the same imaging environment such as the same specialized switching buffers [52-54] or a mounting medium combined with high laser intensities [55], by employing complementary photoactivation schemes [56, 57], or by using dye activator-reporter pairs [58]. Most multicolor approaches are assisted by sophisticated read-out schemes [59-63]. We discuss how to choose appropriate fluorophores to use in a particular study and the parameters that should be taken into account in the next section of this review, where we introduce the basic photophysics and explain how to switch or stabilize fluorophores.

Structural live-cell SMLM imaging of only slowly changing structures can be performed as the imaging speed is fast compared to the phenomenon being imaged. For these structures, it is possible to capture a sufficient number of subsets of fluorophores to fill a subdiffraction sampling space before the structure has changed significantly. Nevertheless, a gain in temporal resolution will always result in a loss of structural spatial resolution caused by lower sampling, and vice versa [55, 64-66]. Uniquely, SMLM can be combined with singleparticle tracking (SPT); unlike diffraction-limited SPT methods, where only a strictly limited number of fluorophores can be followed per cell to keep them separable, sptPALM [67] is readily capable of measuring a large batch of statistics on single-molecule tracks for the same type of molecule inside a single cell by sequential photoactivation. It is thus possible to obtain spatially and temporally highly resolved diffusion maps that combine a multitude of tracks and accordingly unravel possible dynamic heterogeneities and subpopulations. sptPALM has been applied to a wide range of biological systems (some examples are given in [68-70]), and can be combined with structural SMLM imaging [71]. It is nevertheless important to note that the minimum time needed to precisely localize a single fluorophore is influenced by imaging parameters such as the camera sensitivity, the minimum applicable acquisition times (in the range of a few milliseconds), as well as the contrast of the fluorophore (determined by its quantum yield in the specific sample, the laser intensities, and the background noise). This means that sptPALM is only well suited to studying slow diffusion processes, where the fluorophores move slowly compared to the image acquisition time; it is not applicable to processes with faster dynamics such as that visualized in Fig. $1 b$.

\section{Designing the optimal experiment}

\section{Choosing a suitable fluorophore}

Normally, fluorophores reside in their most relaxed molecular state, the electronic ground state $\left(\mathrm{S}_{0}\right)$. When a fluorophore absorbs a photon, it is excited within femtoseconds to a higher energy state $\left(\mathrm{S}_{1}, \mathrm{~S}_{2}, \ldots, \mathrm{S}_{n}\right)$. Depending on the exact energy of 
the absorbed photon, the fluorophore can be excited to various energy levels that correspond to its electronic, vibrational, and rotational molecular configurations. As depicted in Fig. 3a (in which, for simplicity, only the $\mathrm{S}_{0}, \mathrm{~S}_{1}$, and $\mathrm{T}_{1}$ electronic states and the vibrational states for $\mathrm{S}_{1}$ are shown), the fluorophore then relaxes within picoseconds to the lowest level of the excited electronic state $S_{1}$, transferring its vibrational energy to its surroundings.

The time a fluorophore spends in the lowest level of the excited state, often called the fluorescence lifetime, is normally in the nanosecond range, though it depends on the specific molecule and its environment. When returning to the electronic ground state, nonfluorescing molecules release their energy through nonradiative processes such as internal conversion. Fluorophores, on the other hand, exhibit a high probability of a radiative transition; they release energy through the emission of a single fluorescence photon. As a portion of the energy is also lost before this transition through vibrational state relaxation, the fluorescence photon actually has a longer wavelength than the wavelength of the photon originally absorbed. This phenomenon is known as the Stokes shift.

Besides relaxing directly to the ground state through either photon emission or nonradiative internal conversion, an excited fluorophore can release its excess energy by undergoing several other intramolecular and intermolecular processes. Such events decrease the photon yield and are collectively termed quenching. Through the intramolecular transition process known as intersystem crossing, fluorophores can reach an intermediate energy state called the triplet state $\left(T_{1}\right)$. This process involves flipping the spin of the excited electron, and has a miniscule probability (i.e., it is quantum-mechanically forbidden) of occurring during each excitation-relaxation cycle. The triplet state has a much longer lifetime, typically several microseconds, during which the excited molecule remains prone to electron transfer reactions. The result of such a reaction can be a nonfluorescent radical state $\left(\mathrm{F}^{\bullet-}\right)$ in which the fluorophore can remain for several seconds or even minutes. Occasionally it can result in irreversible destruction of the fluorophore through photobleaching processes, leading to a permanent loss of fluorescence. Other dark, nonfluorescent states can be caused by conformational changes in the chromophore, the formation of complexes with other molecules, or a collision with a molecule that is capable of receiving the fluorophore's surplus energy (e.g., oxygen, halogens, and amines). Collisional quenching requires direct proximity of the quencher molecule to the chromophore, and its rate is drastically decreased in fluorescent proteins where the chromophore is protected by its beta-sheet barrel (Fig. 3bi). Finally, the energy of an excited fluorophore can also be transferred to another molecule by photoinduced electron transfer (PET) or Förster resonance energy transfer (FRET), both of which are often exploited in advanced imaging schemes that measure interaction dynamics within or between proteins of interest [82].

The most common types of fluorophores are fluorescent proteins such as GFP (Fig. 3bi) and organic dyes such as rhodamines, carbocyanines, and oxazines (Fig. 3bii). At the heart of every fluorophore is the chromophore, a conjugated $\pi$-electron system that gives a molecule its light-absorbing properties. A chromophore can consist of aromatic rings as well as $\mathrm{C}=\mathrm{C}$, $\mathrm{C}=\mathrm{O}$, or $\mathrm{N}=\mathrm{N}$ bonds. Its spectral properties are determined by the length of the conjugated electronic system, the number of electrons, and different substituents [83]. Usually, elongation of the conjugated system will shift the absorption maximum and thus also the emission maximum to longer wavelengths. This can easily be seen in cyanines, a class of fluorescent dyes with different polymethine chain lengths. Stretching the chain from $\mathrm{Cy} 3$ to $\mathrm{Cy} 7$ shifts the emission spectrum from green to dark red (Fig. 3bii). Every fluorophore thus possesses a unique excitation and emission spectrum. These spectra need to be compatible with the available microscopic system (i.e., in terms of illumination wavelengths, spectral filter combinations, or the sensitivity of the given detector). The excitation and emission wavelengths should be separated by a sufficiently large Stokes shift, and, in multicolor experiments, the chosen set of fluorophores should exhibit sharp and defined spectra with ideally no overlap, thus minimizing crosstalk between the different colors. Alternatively, overlapping spectra can be separated by spectral demixing approaches, which also nicely avoid chromatic aberrations and can allow the use of a single excitation source [60-63]. Sample specifications must also be taken into account; live cells are usually more sensitive to irradiation with shorter-wavelength light; imaging for extended periods of time with light in the ultraviolet (UV) range can lead to a range of defects in cells, from DNA damage to death [84]. Certain biological samples exhibit pronounced autofluorescence in some spectral ranges, usually in shorter wavelengths. The majority of this background fluorescence is caused by aromatic amino acids (mainly tryptophan), the phosphate chain of DNA, intracellular nicotinamide adenine dinucleotide (NADH), and coenzymes [85]. Longer wavelengths of light can penetrate deeper into a tissue, making red and near-infrared fluorophores the most suitable for imaging thicker samples [18].

The chosen fluorophore should be as bright as possible to ensure that sufficient signal is detected to allow it to be distinguished from the background. This is especially crucial for single-molecule imaging when the fluorescence of individual fluorophores is captured. The fluorophore's brightness is determined by its dipole orientation in relation to the excitation light, its extinction coefficient (which quantifies how well a 


\section{a Electronic states}
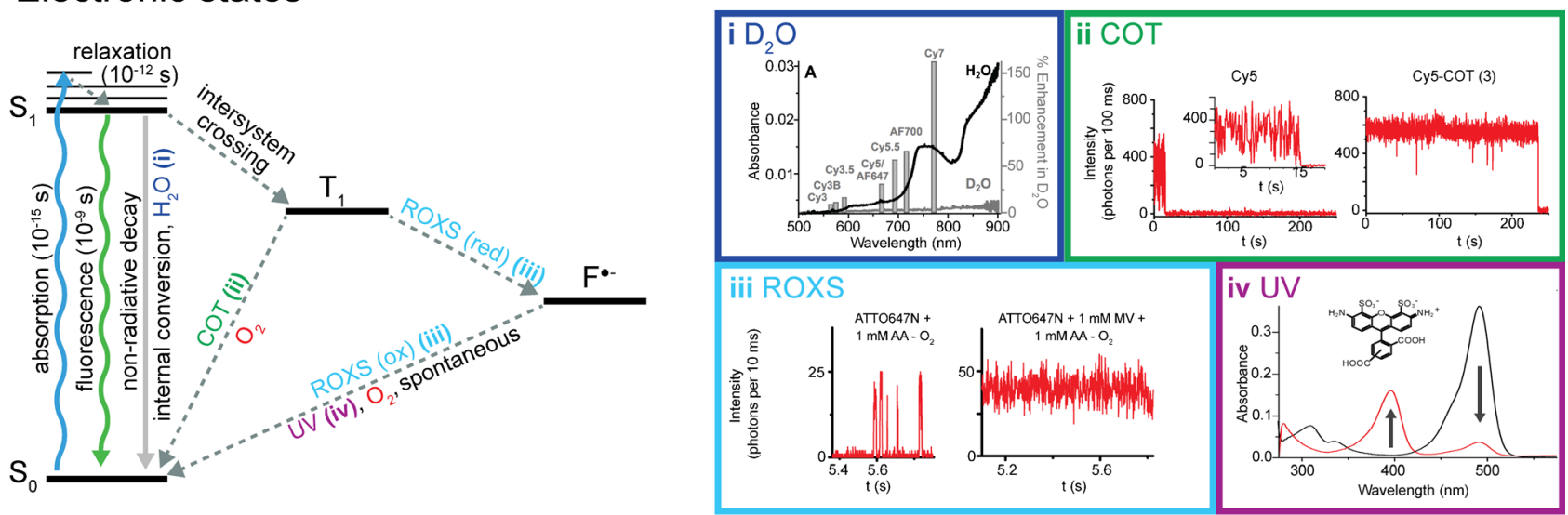

\section{b Fluorophore structures}

i

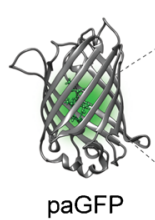

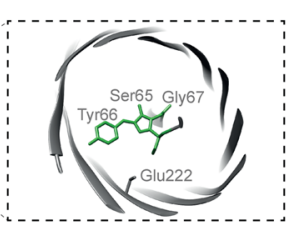

ii

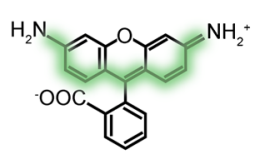

Rhodamines

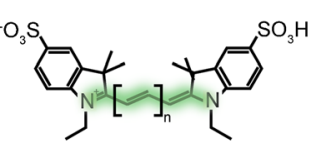

Cy3: $n=1$, Cy5: $n=2$, Cy7: $n=3$

Cyanines

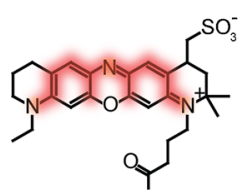

Oxazines

\section{c Photochemical and photoconformational changes}

i

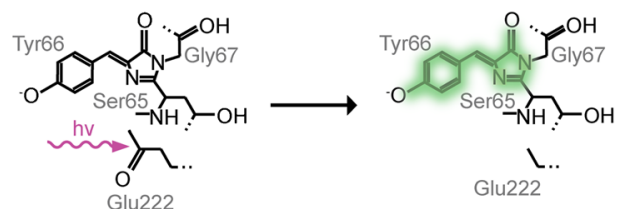

ii

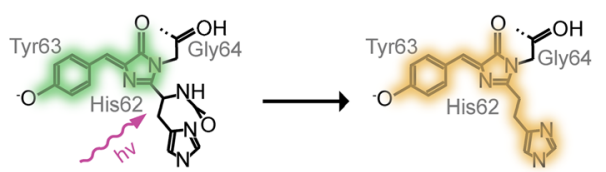

iii

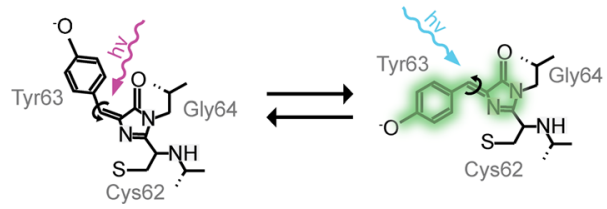

iv<smiles>COc1cc(COC(=O)Nc2ccc3c(c2)Oc2cc(N)ccc2C32c3ccccc3C(=O)OC23CCCCC3)c([N+](=O)[O-])cc1OC</smiles>

$\mathbf{v}$<smiles></smiles>

vi

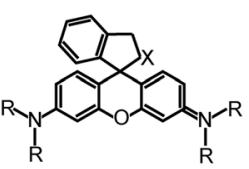

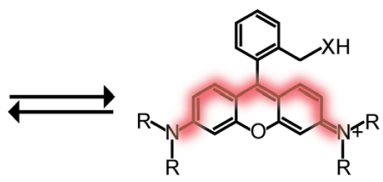

The radical states of some dyes (e.g., the Alexa Fluor 488 fluorophore, as shown in black here; red indicates the radical) possess an absorption peak in the UV range. By exciting the radicals with UV light to higher intermediate states, they can be quickly brought back down to their electronic ground state. Adapted with permission from [75]. b Different fluorophore structures: (i) Barrel structure of the photoactivatable green fluorescent protein (paGFP) and a close-up of its chromophore. (ii) Overview of organic dye classes. c Different photochemical and conformational changes that affect fluorescence: (i) photoactivation of paGFP [76], (ii) green-to-red photoconversion of mEos2 [77], (iii) reversible cis/transphotoswitching of Dronpa [78], (iv) cleavage of a photocage from a rhodamine [79], $(v)$ reversible fluorescence quenching of $\mathrm{Cy} 5$ by covalent binding of a thiol [80], and (vi) reversible cyclization of rhodamine HMSiR [81] 
fluorophore absorbs a certain wavelength), and its quantum yield (the ratio of absorbed to emitted photons). Ideally, the excited fluorophore would emit a single photon in every excitation-emission cycle, thus exhibiting a quantum yield of 1 . However, due to the alternative process of excited-state relaxation described earlier, this is not the case in practice. A fluorophore featuring a relatively low quantum yield can nevertheless produce a sufficient fluorescent signal, provided that its extinction coefficient is high enough and its rate of entry into the excited state is maximized by applying high excitation light intensities, leading to more rapid cycling through the excitation-emission cycle (Fig. 3a).

A constant flux of emitted photons (i.e., the fluorophore's photostability) is another important factor. Fluctuations in fluorescence can be attributed to reversible or irreversible losses of fluorescence, and depend on the chemical properties of the fluorophore, its environment, and the light intensities that it is exposed to. Oxygen and reactive oxygen species play a large role in irreversible bleaching, which is caused by a permanent change in the molecular structure of the fluorophore [86]. Absorption of a second photon while already in the excited state is believed to be another major cause of photobleaching. Low irreversible bleaching rates allow for longer measurements or at higher excitation light intensities. Reversible losses of fluorescence are caused by transitions to several intermediate nonfluorescent electronic or conformational states, as sketched in Fig. 3a. Minimizing the time a fluorophore spends in these states improves the fluorescence signal stability and increases the time that a fluorophore spends performing its excitation-emission cycle, yielding a more constant photon flux.

The solubility and cell permeability of fluorophores must also be considered. Relatively few fluorophores can be transported through a live cell membrane (these are highlighted in Table 2) due to either size or charge constraints. Fluorescent proteins are highly live-cell compatible but can be a steric hindrance in some cases, and can impact cell viability when fused to certain proteins. They have also been shown to form artificial aggregates, depending on the abundance and spatial organization of the target molecule [122].

Importantly, each super-resolution technique has special demands. The most common fluorophores employed, their properties, and (in the case of SMLM) the most popular multi-color combinations are given in Table 2. In STED, the molecules are constantly forced from the excited state into the electronic ground state via stimulated emission. Fluorophores with high extinction coefficients, high quantum yields, and high stimulated emission cross-sections are favorable, as they allow for the best possible contrast in the detection of the fluorescing fluorophores left in the center of the excitation pattern. The rate of stimulated depletion of the excited state scales with the depletion energy applied, so fluorophores chosen for STED have to be exceptionally photostable. Further, the depletion wavelength should be carefully chosen to ensure that it does not re-excite any of the fluorophores that are depleted to the ground state. For SIM, the most crucial parameters are the photostability and overall brightness of the fluorophore, as the technique works by measuring the fluorescence response of a defined patterned excitation. This modulation of fluorescence should be clearly detectable based on a strong and inherently stable fluorescence signal. Since illumination-independent fluctuations in fluorescence result in artifacts, the use of an effective antifading agent is common practice. Almost all modern fluorophores can be used for SIM (which is why we do not provide a selection of SIM fluorophores in Table 2). Finally, for SMLM techniques, rigid control of photoswitching is crucial. The nonfluorescing dark times of the fluorophores must be long enough to guarantee the separation of single-molecule signals in the sample at any time during the experiment. Even when applying algorithms that can handle high numbers of fluorescent molecules at a time, the techniques are easily impaired when the density of molecules is too high [123].

The dye Alexa Fluor 647 is the fluorophore of choice in a great majority of fixed cell SMLM studies, due to its robust photoswitching and good photon yields. Since it is not membrane permeable, ATTO 655, tetramethylrhodamine, SiR, and Oregon Green are utilized in most live cell studies. When multicolor imaging is desired, Alexa Fluor 568 and 532 are often used with Alexa Fluor 647. Fluorescent proteins are more suitable for quantitative approaches or noninvasive live cell studies. A collection of popular fluorophores as well as multicolor schemes is provided in Table 2. In this context, different photoswitching strategies (as evaluated in detail below) require individual optimizations such as customized specific photoactivation and photoconversion efficiencies for convertible fluorophores that allow for sequential activation [57] and tailored imaging buffers for selected organic dyes.

Even more complex imaging experiments involve additional considerations, such as the need to carefully choose the spectral overlap between donor emission and acceptor excitation for optimal FRET, the selection of appropriate strategies for optimal multiphoton absorbance or when utilizing fluorophores as biosensors [82].

\section{Labeling strategies}

Choosing a strategy to label the biomolecule of interest is a crucial part of the experiment. Luckily, strategies suitable for many biological applications are commercially available and, for the best results, experiments should be planned with the labeling strategy in mind from the very beginning. It is important to emphasize that it is always the label attached to the molecule of interest that is visualized, not the molecule itself - the signal we see on the microscope is a label's length away. Using large labels in combination with high resolutions 
Table 2 List of recommended and promising new fluorophores for super-resolution microscopy

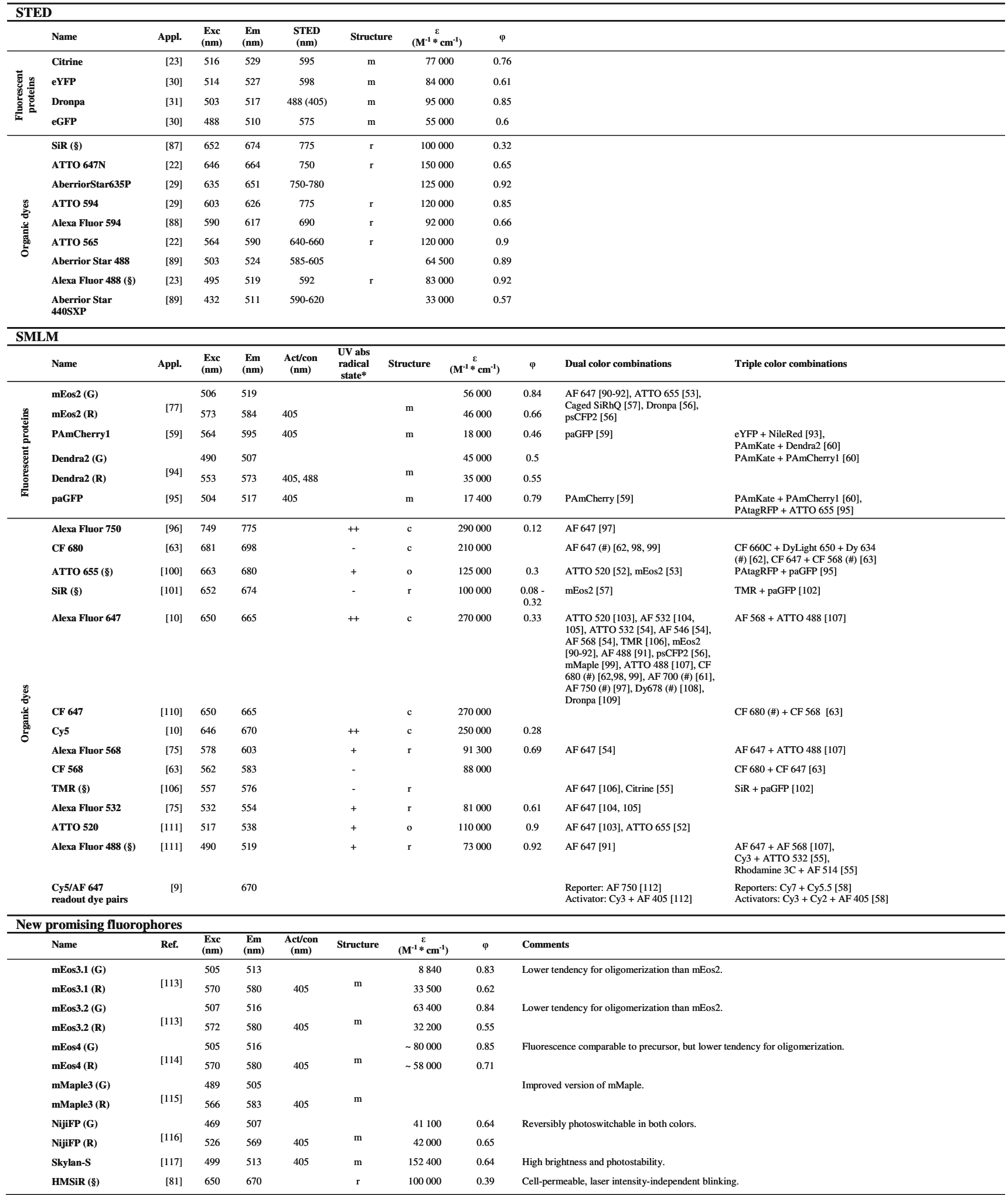

Numbers are taken from the manufacturers and from [59, 77, 81, 94, 101, 113-120]

Appl Example of the use of the fluorophore for super-resolution microscopy, Exc excitation peak, Em emission peak, Act/con activation or conversion wavelength, $\varepsilon$ molar extinction, $\varphi$ quantum yield, $m$ monomeric, $c$ cyanine, $o$ oxazine, $r$ rhodamine, ( $\S$ ) cell-permeable dyes

* [75, 121]; (\#) spectral demixing 
Table 3 Summary of labeling strategies commonly used in super-resolution microscopy

\begin{tabular}{|c|c|c|c|c|c|c|}
\hline & Label & Appl. & Size & Description & Possible uses & Considerations \\
\hline \multirow{8}{*}{ 童 } & \multirow{5}{*}{$\begin{array}{l}\text { Antibody } \\
\text { IgG or Fab } \\
\text { fragment }\end{array}$} & \multirow[t]{5}{*}[125]{} & \multirow{5}{*}{$\begin{array}{l}\text { Up to } \\
20 \mathrm{~nm}\end{array}$} & \multirow{3}{*}{$\begin{array}{l}\text { IgG: antigen-specific } \\
\text { immunoglobulin } \mathrm{G} \text { antibodies } \\
\text { consisting of two identical heavy } \\
\text { chains and two identical light } \\
\text { chains arranged in a Y-shape. }\end{array}$} & \multirow{5}{*}{$\begin{array}{l}\text { Classic immunofluorescence by } \\
\text { primary and secondary antibody } \\
\text { combination. }\end{array}$} & Requires no genetic modification of the target. \\
\hline & & & & & & $\begin{array}{l}\text { Modular, as secondary antibodies are available } \\
\text { for a wide range of fluorophores. }\end{array}$ \\
\hline & & & & & & Large tags which limit the image resolution. \\
\hline & & & & \multirow{2}{*}{$\begin{array}{l}\text { Fab: antigen-specific monovalent } \\
\text { fragments from IgG and IgM, } \\
\text { consisting of the variable regions } \\
\text { of both heavy and light chains } \\
\text { linked by a disulfide bond. }\end{array}$} & & $\begin{array}{l}\text { Not cell-permeable, thus limiting live-cell } \\
\text { staining as specialized delivery method is } \\
\text { needed. }\end{array}$ \\
\hline & & & & & & Prone to background from nonspecific labeling. \\
\hline & \multirow[t]{3}{*}{ Nanobody } & \multirow[t]{3}{*}[4,126]{} & \multirow[t]{3}{*}{$\sim 3 \mathrm{~nm}$} & \multirow{3}{*}{$\begin{array}{l}\text { Antigen-specific single variable } \\
\text { domain (VHH) of single-chain } \\
\text { antibody with nanomolar affinity. }\end{array}$} & \multirow{3}{*}{$\begin{array}{l}\text { Live-cell stain by recombinant } \\
\text { expression of antigen-specific } \\
\text { nanobody and fluorescent protein } \\
\text { in living cells. } \\
\text { Classic immunofluorescence } \\
\text { stain without the need for a } \\
\text { secondary antibody. }\end{array}$} & Anti-GFP nanobody is a popular stain. \\
\hline & & & & & & $\begin{array}{l}\text { Live-cell stain results in nonspecific background } \\
\text { due to lack of washing. }\end{array}$ \\
\hline & & & & & & Prone to background in SMLM. \\
\hline \multirow{5}{*}{ 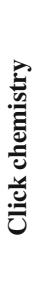 } & \multirow[t]{2}{*}{$\begin{array}{l}\text { Unnatural } \\
\text { amino acids }\end{array}$} & \multirow[t]{2}{*}[127]{} & \multirow[t]{5}{*}{$<1 \mathrm{~nm}$} & \multirow{5}{*}{$\begin{array}{l}\text { Not naturally occurring and } \\
\text { chemically reactive cell } \\
\text { component analogues, mostly } \\
\text { with alkyne or azide groups for } \\
\text { Huisgen cycloaddition. }\end{array}$} & \multirow{5}{*}{$\begin{array}{l}\text { Nonspecific labeling of newly } \\
\text { synthesized proteins, membranes, } \\
\text { nucleic acids. } \\
\text { Pulse labeling for a short time } \\
\text { period. } \\
\text { Site-specific labeling of proteins } \\
\text { by codon reassigment methods. }\end{array}$} & $\begin{array}{l}\text { Require no genetic modification of the target for } \\
\text { nonspecific incorporation. }\end{array}$ \\
\hline & & & & & & Modular, as a large selection of fluorophores \\
\hline & Unnatural & [128] & & & & with reactive groups are available. \\
\hline & IIpIas & & & & & $\begin{array}{l}\text { Incorporatıon of analogues may impact cell } \\
\text { physiology. }\end{array}$ \\
\hline & $\begin{array}{l}\text { Unnatural } \\
\text { nucleotides }\end{array}$ & {$[129]$} & & & & $\begin{array}{l}\text { Live-cell staining only possible for cell- } \\
\text { permeable fluorophores or a specialized delivery } \\
\text { method. }\end{array}$ \\
\hline \multirow{4}{*}{$\frac{\sqrt{5}}{2}$} & \multirow[t]{4}{*}{$\begin{array}{l}\text { Fluorescent } \\
\text { oligonucleotides }\end{array}$} & \multirow[t]{4}{*}[130]{} & \multirow[t]{4}{*}{$<1 \mathrm{~nm}$} & \multirow[t]{4}{*}{$\begin{array}{l}\text { Fluorescently labeled } \\
\text { oligonucleotides }\end{array}$} & \multirow{4}{*}{$\begin{array}{l}\text { Sequence-specific } 16 \mathrm{~S} \text { rRNA } \\
\text { stain. } \\
\text { Specific gene/genetic region } \\
\text { DNA stain. } \\
\text { RNA stain. }\end{array}$} & $\begin{array}{l}\text { Highly modular: various oligonucleotides can be } \\
\text { designed and coupled to a large selection of }\end{array}$ \\
\hline & & & & & & fluorophores. \\
\hline & & & & & & Limited compatibility with live-cell studies due \\
\hline & & & & & & to harsh hybridization conditions. \\
\hline \multirow{8}{*}{ 胥 } & MitoTracker & {$[35]$} & \multirow[t]{8}{*}{$<1 \mathrm{~nm}$} & \multirow{8}{*}{$\begin{array}{l}\text { Various small molecules that } \\
\text { bind to specific targets. }\end{array}$} & \multirow{8}{*}{$\begin{array}{l}\text { Staining of fixed cells. } \\
\text { Live-cell staining for cell- } \\
\text { permeable drugs. }\end{array}$} & Large selection of drugs coupled to various \\
\hline & LysoTracker & [131] & & & & fluorophores. \\
\hline & Phalloidin & {$[87]$} & & & & Live-cell staining only possible for cell- \\
\hline & SiR-Tubulin & {$[132]$} & & & & $\begin{array}{l}\text { permeable fluorophores or specialized delivery } \\
\text { method. }\end{array}$ \\
\hline & $\begin{array}{l}\text { SiR-Actin } \\
\text { SiR-DNA }\end{array}$ & $\begin{array}{l}{[132]} \\
{[133]}\end{array}$ & & & & \\
\hline & DAPI & {$[37]$} & & & & \\
\hline & mCling & {$[134]$} & & & & \\
\hline & LifeAct & [13] & & & & \\
\hline & SNAP & [135] & $\sim 3 \mathrm{~nm}$ & $\begin{array}{l}\text { Genetic fusion of ligand binding } \\
\text { enzyme to protein of interest. }\end{array}$ & $\begin{array}{l}\text { Stable cell line under endogenous } \\
\text { promoter. }\end{array}$ & $\begin{array}{l}\text { Large selection of ligands coupled to various } \\
\text { fluorophores. }\end{array}$ \\
\hline & CLIP & [136] & & & $\begin{array}{l}\text { Transient plasmid with } \\
\text { known/inducible expression. }\end{array}$ & $\begin{array}{l}\text { Require an additional staining step which is } \\
\text { highly specific and covalent. }\end{array}$ \\
\hline & HALO & {$[137]$} & & & $\begin{array}{l}\text { Staining with ligand coupled to } \\
\text { fluorophore of choice. }\end{array}$ & $\begin{array}{l}\text { Genetic fusion may interfere with protein } \\
\text { localization and function. }\end{array}$ \\
\hline 气̊ & eDHFR & [138] & & & & $\begin{array}{l}\text { Live-cell staining only possible for cell- } \\
\text { permeable fluorophores or specialized delivery } \\
\text { methods. }\end{array}$ \\
\hline$\stackrel{\mathscr{e}}{E}$ & Fluorescent & {$[118]$} & $\sim 3 \mathrm{~nm}$ & Genetic fusion of fluorophore to & Stable cell line under endogenous & Live-cell imaging. \\
\hline$\stackrel{\mathscr{U}}{巳}$ & & & & $\mathrm{pr}$ & promoter. & No need for staining step adding external \\
\hline 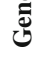 & & & & & $\begin{array}{l}\text { Transient plasmid with } \\
\text { known/inducible expression. }\end{array}$ & $\begin{array}{l}\text { fluorophores during the sample preparation. } \\
\text { Highly specific tag. }\end{array}$ \\
\hline & & & & & & $\begin{array}{l}\text { Genetic fusion may interfere with protein } \\
\text { localization and function. }\end{array}$ \\
\hline & & & & & & $\begin{array}{l}\text { Factors like maturation time or misfolding must } \\
\text { be taken into account. }\end{array}$ \\
\hline & & & & & & $\begin{array}{l}\text { Some fluorescent proteins tend to artificially } \\
\text { aggregate for concentrations above a certain } \\
\text { threshold. }\end{array}$ \\
\hline
\end{tabular}

can thus lead to artificial inflation of the structure [4, 5]. The size and dipole orientation of the fluorophore and the achievable labeling density directly impact the resolution attained.
High density — which requires at least an average nearestneighbor label distance of less than twice the sampling rate according to the Shannon-Nyquist criterion-is necessary 
[124], or important sample information can be missed. Here, we evaluate the common strategies used (see also Table 3).

Affinity-based labeling is probably the approach most widely used across all fluorescence microscopy applications $[104,105,125,139]$. Antibodies can target virtually any cellular component as an antigen, making the technique extremely flexible. Using combinations of primary and secondary antibodies also makes the approach very modular. Nevertheless, the technique suffers from several drawbacks. First, background due to nonspecific staining is quite common [140], and antibodies may detach from their targets when irradiated with high laser intensities [141]. Second, a typical primary and secondary antibody combination is $\sim 20 \mathrm{~nm}$ in size, which is sufficient to cause imaging artifacts at resolutions realized in super-resolution microscopy. Nanobodies [4], $\sim 3 \mathrm{~nm}$ single-variable domains of single-chain antibodies isolated from cameloids, virtually eliminate this size problem. They can also be fused to fluorescent proteins and recombinantly expressed in live cells [126]. Aptamers - small RNA structures that function much like antibodies and are suitable for live-cell staining [142] — are worth mentioning, though their use is currently limited by poor availability. Much promise is shown by the GFP mimic family of aptamers, which form a GFP-like chromophore when bound to a nonfluorescent substrate [143].

Click chemistry is the term used to describe a set of reactions that occur at high yields in aqueous environments under mild conditions. It thus allows for effective labeling of biomolecules based on the incorporation of unnatural analogues of amino acids [127], nucleotides [129], or lipids [128] carrying a reactive chemical group such as an alkyne, azide, or cyclooctene into cellular structures. Fluorophores carrying the complementary group can then be covalently bound via (for example) cycloaddition [129]. Live-cell imaging is possible with some modifications [144]. This method is suitable for imaging DNA, RNA, proteins, and membranes, and produces very low background fluorescence but usually does not target specific biomolecules. Genetically programmable site-specific unnatural amino acid incorporation can be realized by codon reassignment $[145,146]$.

Fluorescence in situ hybridization (FISH) [130] allows nucleic acids to be labeled by complementary oligonucleotide probes coupled to fluorophores. The technique is often employed with $16 \mathrm{~S}$ rRNA complementary probes to study microbe communities [147]. In super-resolution applications, it is a powerful tool for studying chromatin structure and organization, gene location [148, 149], RNA localization and quantification [148], telomere structure [150], etc. As the hybridization protocols involve harsh chemical and temperature treatments, this technique has limited live-cell compatibility.

Engineered ligand-binding enzymes which are genetically fused to the protein of interest are the basis of protein tags such as SNAP [135], CLIP [136], HALO [137], and eDHFR [138]. Such an enzyme label can then be stained by covalently binding its fluorophore-bound specific ligand (benzylguanine, benzylcytosine, chloroalkanes, and trimethoprim, respectively). Such ligands can be fused to virtually any fluorophore, which makes these tags very popular in multicolor applications [66, 95, 106].

Specific labeling options are available for several targets. Fluorescently labeled phalloidin is a toxin commonly used as a filamentous actin stain [87]. SiR-actin, SiR-tubulin [132], and LifeAct [13] are live-cell cytoskeleton stains. Some fluorescently labeled lipid analogues [151] and the recently developed mCling peptide [134] have been used as direct membrane stains. Other target-specific drugs include organelle specific probes such as the mitochondrion stain MitoTracker [35], the lysosome stain LysoTracker, or the ER stain ER-Tracker [131].

All these methods require the introduction of an extrinsic fluorophore into the cell. In fixed cells, this is usually not an issue, and this process can be greatly facilitated by introducing a permeabilization step in which the cell membrane or wall is perforated. Live-cell applications necessitate the use of membrane-permeable fluorophores such as the rhodamine dyes SiR [101], TMR-STAR [106], and Oregon Green [66] and, to a lesser degree, some oxazine dyes such as ATTO 655 [95]. Membrane permeability can be improved by performing certain modifications such as fusion to a permeable peptide [152]. Many alternative strategies for fluorophore delivery, such as electroporation, bead loading, membrane transfer, and micro- or nanoinjection techniques have been developed over the years [153-157].

The discovery and subsequent cloning of green fluorescent protein (GFP) [158] introduced the possibility of small, endogenous, and inherently fluorescent labels. Fluorescent protein fusions, which require no further staining, have become a widespread labeling strategy and are available in a variety of colors [118]. They are highly suited to live-cell studies as long as the cells are carefully checked for physiology after the genetic modification. Unfortunately, they exhibit relatively poor photostability and at best a fifth of the brightness of organic dyes [159]. Since the resolution achievable in SMLM increases with the square root of the amount of photons emitted by a single fluorophore, this can directly impact the resolution of SMLM [46]. Factors such as protein folding as well as the efficiency and velocity of chromophore maturation are important and can differ depending on the environment, e.g., the presence of molecular oxygen is usually needed for final chromophore maturation [160, 161]. Their properties can be readily modified by changing the amino acid sequence, and several versions have been designed to have improved brightness and photostability [162] and switching properties for SMLM imaging. These include photoactivatable proteins such as paGFP [119] and PAmCherry1 [59], reversibly switchable FPs such as Dronpa [120] and Dreiklang [163], and photoconvertible FPs such as Kaede [164], mEos2 [77], or Dendra2 [94]. An often overlooked factor is codon usage 
bias, and all endogenous tags, including self-labeling enzymes, should be codon-optimized for the organism used [165].

\section{Controlling the fluorescence of the sample}

Robust control of the molecular states is crucial in most superresolution microscopy applications. Certain steps can be taken to improve the stability, longevity, and intensity of fluorescence, as well as to achieve the on and off switching required for SMLM.

Considering that most microscope cameras record with millisecond-range exposure times, triplet-state transitions and collisional quenching events - which occur several orders of magnitude faster than these exposure times - are not registered as individual events but rather as a loss of signal intensity. Collisional quenching is mostly avoided by imaging in defined, impurity-free buffer solutions, though water shows absorbance in the visible range of light due to its molecular vibrations, as shown in Fig. 3ai. When these molecular vibrations are in resonance with the emission wavelength of a fluorophore, the fluorophore can transfer its excited-state energy to a water molecule during a collision. Heavy-water $\left(\mathrm{D}_{2} \mathrm{O}\right)$ molecules vibrate at significantly lower frequencies due to the presence of deuterium. Substituting water in the imaging solution with $\mathrm{D}_{2} \mathrm{O}$ thus increases the overall photon yield. The magnitude of fluorescence enhancement in $\mathrm{D}_{2} \mathrm{O}$ versus $\mathrm{H}_{2} \mathrm{O}$ for a specific fluorophore thus correlates with the spectral overlap of the light absorption of $\mathrm{H}_{2} \mathrm{O}$ with the emission of the fluorophore, as seen for different fluorophores in Fig. 3ai [72].

Molecular oxygen plays an important role in many of the fluorophore's electronic state transitions. Since the ground state of molecular oxygen is also a triplet, it easily reacts with a triplet-state fluorophore in an electron transfer reaction. This can return the fluorophore to its ground state, but it also produces singlet oxygen and reactive oxygen species (ROS), which can then cause irreversible photobleaching [86]. To avoid the bleaching caused by a buildup of ROS, oxygen can be removed from the imaging solution by adding enzymatic systems such as a combination of glucose oxidase, glucose, and catalase (GLOX) [166], a mix of protocatechuate dioxygenase and protocatechuic acid (PCA/PCD) [167], or a system containing pyranose oxidase, glucose, and catalase [168], as summarized in Table 4. It is worth mentioning that it has recently been reported that most commercial glucose oxidase preparations used in the popular GLOX system suffer from nuclease contamination. Such contamination can cause fluorescent background and introduce artifacts into nucleic acid studies. Furthermore, the GLOX reaction lowers the $\mathrm{pH}$ of the solution over time, while other systems do not [177]. Fast, efficient chemical oxygen removal has also been reported to be achieved with methylene blue (MB) and mercaptoethylamine (MEA) [170].

However, since oxygen is such an efficient triplet-state quencher, its depletion can result in a high fraction of fluorophores populating the triplet state, significantly impairing the photon yield. There are several strategies that enable us to circumvent this problem while still removing the risk of bleaching by ROS. The first is to add the chemical cyclooctatetraene (COT), which, much like oxygen, directly returns triplet-state fluorophores to their ground states. As this process significantly shortens the residence time of the fluorophore in the triplet state, the overall fluorescence is stabilized and intensity fluctuations are reduced, as shown in Fig. 3aii [73, 176].

The second approach is to quench the triplet state by colliding the fluorophore with certain reducing agents, thus converting it into the dark, nonfluorescent, anionic radical form $\mathrm{F}^{\bullet-}$, as shown in Fig. 3aiii. To do this, chemicals such as mercaptoethylamine (MEA) $[176,178], \beta-$ mercaptoethanol (BME) [166], dithiothreitol (DTT) [111], glutathione (GSH) [111], 6-hydroxy-2,5,7,8tetramethylchroman-2-carboxylic acid (Trolox) [174, 179], ascorbic acid (AA) [74], and potassium iodide (KI) [180] can be added to the imaging buffer. However, to return to the ground state, the $\mathrm{F}^{\bullet-}$ fluorophore must be oxidized, a task in which oxygen again plays a crucial role. Removing oxygen can thus lead to very long $\mathrm{F}^{\bullet-}$ dark states, a property exploited in SMLM. Using high excitation light intensities ensures that the fluorophores are quickly cycled into the triplet state, from where they are promptly reduced to the dark radical state. Cyanine fluorophores such as Alexa Fluor 647 require a primary thiol (e.g., BME, MEA, GSH, or DTT) in the switching buffer, and undergo a thiol group addition reaction at one of the $\mathrm{C}$ atoms in the $\pi$-system (Fig. $3 \mathrm{cv}$ ) [80]. A similar effect can be observed with a phosphine group upon the addition of tris(2-carboxyethyl)phosphine (TCEP) [172]. Since complete oxygen removal is impossible, the few residual oxygen molecules can stochastically oxidize individual fluorophores into the ground state, causing the on and off fluorescence "blinking" desired in SMLM. Many fluorophores develop a distinct absorption peak at shorter wavelengths in their radical state, likely due to disruption of the $\pi$-system. Indeed, in cyanine dyes, this system is thought to be practically split in two [80]. Irradiation by UV light thus expedites the return of $\mathrm{F}^{\bullet-}$ fluorophores to the ground state [75], as depicted in Fig. 3aiv. Embedding samples in resin greatly suppresses collisional interactions, meaning that reactivation by UV is the only means of returning to the ground state [64], making the method viable for correlative light electron microscopy [181].

Oxygen in the solution can also be replaced with an alternative oxidizer such as methylviologen (MV) [74] or Trolox, which can be converted into an oxidizing quinone form upon UV irradiation [174]. The blinking rate can be adjusted by 
Table 4 Summary of labeling strategies commonly used in super-resolution microscopy

\begin{tabular}{|c|c|c|c|c|c|}
\hline & Buffer class & Buffer base & Compounds & Organic dyes used in switching buffer / description & Ref. \\
\hline \multirow{21}{*}{ 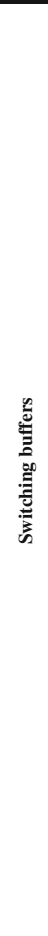 } & \multirow{3}{*}{$\begin{array}{l}\text { Reducer } \\
-\mathrm{O}_{2}\end{array}$} & \multirow{3}{*}{$\begin{array}{l}\mathrm{PBS} / \text { TRIS } \\
\mathrm{pH} 7.4-9 \\
-\mathrm{O}_{2}\end{array}$} & $10-100 \mathrm{mM}$ MEA & AF 750 [96], CF 680 [63], CF 647 [63], AF 647 and Cy5 [10], CF 568 [63], AF 532 [106], ATTO 520 [103] & [10] \\
\hline & & & $0.5-1 \%$ BME & AF 750 [112], CF 680 [98], Cy5 readout pairs [9, 58], AF 647 [92] & [58] \\
\hline & & & 10 - $100 \mathrm{mM} \mathrm{GSH}$ & AF 647 [106], TMR [106] & [106] \\
\hline & \multirow{5}{*}{ Reducer only } & \multirow{5}{*}{$\begin{array}{l}\text { PBS/TRIS } \\
\mathrm{pH} 7.4-9\end{array}$} & $10-100 \mathrm{mM}$ MEA & AF 647 [54], ATTO 655 [100], AF 568 [54], ATTO 520 [111], AF 532 [105], AF 488 [111] & {$[52,111]$} \\
\hline & & & $0.5-1 \%$ BME & ATTO $655[100]$ & [100] \\
\hline & & & $50 \mu \mathrm{M} \mathrm{AA}$ & ATTO 655 [169] & [169] \\
\hline & & & $10-100 \mathrm{mM} \mathrm{GSH}$ & ATTO 655 [52], АTTO 520 [52] & {$[52,111]$} \\
\hline & & & $50 \mathrm{mM}$ TCEP + $2 \mathrm{mM}$ COT & $\mathrm{AF} 750$ [97], AF 647 [97] & [97] \\
\hline & \multirow{4}{*}{ o } & \multirow{4}{*}{$\begin{array}{l}\text { PBS/TRIS } \\
\text { pH 7.4-9 }\end{array}$} & GLOX* & AF 568 [121], ATTO 520 [121], AF 488 [121] & [121] \\
\hline & & & PCD/PCA* & & [167] \\
\hline & & & POC* & & [168] \\
\hline & & & $100 \mathrm{mM}$ MEA $+1 \mu \mathrm{M}$ MB & Су5 [170] & [170] \\
\hline & \multirow{2}{*}{$\begin{array}{l}\text { Switching } \\
\text { ROXS } \\
\text { reducer and } \\
\text { oxidizer } \\
-\mathrm{O}_{2}\end{array}$} & \multirow{2}{*}{$\begin{array}{l}\mathrm{PBS} / \mathrm{TRIS} \\
\mathrm{pH} 7.4-9 \\
-\mathrm{O}_{2}\end{array}$} & $500 \mu \mathrm{M} \mathrm{AA}+25 \mu \mathrm{M} \mathrm{MV}$ & ATTO 655 [171] & [171] \\
\hline & & & $\begin{array}{l}1 \mathrm{mM} \mathrm{AA} \mathrm{+} 1 \mathrm{mM} \mathrm{MV}+ \\
25 \mathrm{mM} \text { TCEP, pH } 9\end{array}$ & $\mathrm{AF} 750$ [172], AF 647 [172], Cy5 [172] & [172] \\
\hline & \multirow{4}{*}{$\begin{array}{l}\text { Switching } \\
\text { mount }\end{array}$} & Vectashield & $\begin{array}{l}20 \% \text { Vectashield + 80\% (95\% } \\
\text { glycerol } 50 \mathrm{mM} \text { TRIS) }\end{array}$ & AF 647 [110], CF 647 [110] & [110] \\
\hline & & Mowiol & $0.5 \%$ Mowiol + $50 \mathrm{mM}$ DTT & $\operatorname{SiR}[101]$ & [101] \\
\hline & & Resin & $\begin{array}{l}100 \% \text { dehydration + EM resin } \\
\text { embedding }\end{array}$ & & [173] \\
\hline & & PVA & $1 \%$ in PBS, spin coat & Oregon Green [41], AF 488 [41] & [41] \\
\hline & \multirow{3}{*}{$\begin{array}{l}\text { Live-cell } \\
\text { media }\end{array}$} & \multirow{3}{*}{$\begin{array}{l}\text { DMEM, modified to } \\
\text { not contain phenol red }\end{array}$} & None & $\operatorname{SiR}[102], \operatorname{TMR}[55,102]$ & [55] \\
\hline & & & $100 \mathrm{mM}$ GSH + GLOX & AF 647 [106], TMR [106] & [106] \\
\hline & & & $25 \mathrm{mM}$ TCEP & AF 647 [172], Cy5 [172] & [172] \\
\hline \multirow{6}{*}{ 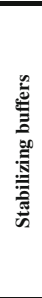 } & \multirow{2}{*}{$\begin{array}{l}\text { Stabilizing } \\
\text { ROXS } \\
\text { reducer and } \\
\text { oxidizer } \\
-\mathrm{O}_{2} \\
\end{array}$} & \multirow{2}{*}{$\begin{array}{l}\mathrm{PBS} / \mathrm{TRIS} \\
\mathrm{pH} 7.4-9 \\
-\mathrm{O}_{2}\end{array}$} & $1 \mathrm{mM} \mathrm{AA}+1 \mathrm{mM}$ MV & Triplet-state quenching and fluorescence stabilizer. & [74] \\
\hline & & & $1 \mathrm{mM}$ Trolox + Trolox-quinone & Triplet-state quenching and fluorescence stabilizer. & [174] \\
\hline & \multirow{4}{*}{ Mounting } & Vectashield & & & \\
\hline & & Mowiol & Sample mount & Sample mounting media that retard photobleaching, stabilize fluorescence, and can be used for longer-term & [175] \\
\hline & & SlowFade & Sampie mount & sample preservation (Mowiol). & {$[1 / 2]$} \\
\hline & & Fluor-Stop & & & \\
\hline \multirow{4}{*}{ 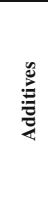 } & \multirow{2}{*}{$\begin{array}{l}\text { TSQ } \\
\text { triplet-state } \\
\text { quenchers }\end{array}$} & Cyclooctatetraene & $2 \mathrm{mM} \mathrm{COT}$ & Direct triplet-state quenching by energy transfer. & {$[73,176]$} \\
\hline & & Nitrobenzyl alcohol & $2 \mathrm{mM} \mathrm{NBA}$ & Fluorescence enhancer and stabilizer, redox triplet quencher. & [73] \\
\hline & \multirow{2}{*}{$\begin{array}{l}\text { Antifading } \\
\text { agents }\end{array}$} & n-Propyl gallate & $10-100 \mu \mathrm{M}$ NPG & Antioxidant fluorescence protectant. & [176] \\
\hline & & $\begin{array}{l}\text { 1,4-Diazabicyclo } \\
\text { [2.2.2]octane }\end{array}$ & $10 \mathrm{mM}-1 \mathrm{M}$ & Antifading agent. & [167] \\
\hline
\end{tabular}

The switching buffers section of the table includes a list of working dye/buffer combinations. Example buffer compilation: decide on buffer class (e.g.,

"Reducer with $-\mathrm{O}_{2}$ "), and then decide on the buffer base, the $\mathrm{pH}$, oxygen removal $\left(-\mathrm{O}_{2}\right)$, and the final compounds based on the fluorophore used (e.g., CF 680 with 10-100 mM MEA [63])

AF Alexa Fluor, $-\mathrm{O}_{2}$ oxygen removal, for the abbreviations of the chemicals, see the text or the corresponding references

* For the exact formulations of GLOX, PCD/PCA, and PCO, see the corresponding references

fine-tuning the ratios of these compounds while keeping the reducer at a high concentration and the oxidizer at a low concentration [171]. The exact concentrations heavily depend on the redox potentials of the fluorophore-reducer/oxidizer pairs. Since the reduction potential of the $\mathrm{F}^{\bullet-}$ state varies with the fluorophore considered, different fluorophores can exhibit different blinking behaviors in the same buffer. The $\mathrm{pH}$ influences the redox potentials of the compounds in the solution, so changing the $\mathrm{pH}$ provides yet another way of adjusting blinking rates [111]. For some fluorophores, the reducing environment inside living cells is sufficient to induce long dark states [106]. In some cases, oxygen removal can be omitted and the addition of a reducer is sufficient [169].

In the cases of STED and SIM, the same strategy can be used to stabilize the fluorescence. Provided the concentrations of both the reducer and the oxidizer are high enough (usually in the millimolar range), the triplet state is efficiently reduced to a radical state that is rapidly oxidized back to the ground state upon formation. The rapidity of this process of reduction and oxidation significantly shortens the overall time the fluorophore spends in nonfluorescing states. The stabilizing effects of a reducing and oxidizing system (ROXS) such as 
that shown in Fig. 3aiii were reported before the development of SMLM [74].

Fluorophores can also be protected from bleaching by the addition of antioxidants such as $n$-propyl gallate (nPG) [176] or antifading reagents such as nitrobenzyl alcohol (NBA), paraphenylenediamine (PPD), 1,4-diazabicyclo[2.2.2] octane (DABCO), and commercial products such as Vectashield, Fluor-stop, Mowiol, or SlowFade [175, 182]. Vectashield has also been reported to be an effective and very simple SMLM switching medium for several dyes, acting through an unspecified mechanism [110]. COT, NBA, and Trolox have also been (covalently) linked to fluorophores, introducing the concept of "self-healing" dyes [183]. All of these components as well as some popular SMLM buffer formulations that facilitate photoswitching of common fluorophores are summarized in Table 4.

In addition to electronic state transitions, switching is also caused by conformational changes in the chromophore or its surrounding environment. Three main conformational blinking mechanisms exist in fluorescent proteins: photoactivation, photoconversion, and photoswitching [184]. In photoactivatable fluorescent proteins such as paGFP, interactions between the chromophore and a side chain in the beta-barrel stabilize the conjugated $\pi$-system in a neutral nonfluorescent state. Irradiation with UV decarboxylates the side chain, shifting the equilibrium of the chromophore towards its anionic state, thus making the protein fluorescent (Fig. 3ci) [76]. Similarly, photoconvertible fluorescent proteins such as mEos2 [77] undergo a fluorescence wavelength shift from green to orange when a peptide bond in the chromophore is cleaved by UV irradiation, causing an extension of the $\pi$-system, as seen in Fig. 3cii [185]. Finally, photoswitchable fluorescent proteins undergo reversible on and off switching as a result of UV-induced cis/trans isomerization like that shown for the fluorescent protein Dronpa in Fig. 3ciii. The isomerization causes protonation changes similar to those that occur in photoactivatable proteins, but which result in the reversible formation of a nonfluorescent form of the fluorophore [78]. Switching properties of fluorescent proteins can be adjusted by modifying the amino acid sequence. Two interesting examples of this are IrisFP and NijiFP [116], which can both be irreversibly photoconverted by UV light from their initial green fluorescing form into an orange fluorescing form, as well as reversibly photoswitched between their fluorescing and dark state (in both the green and the orange fluorescent forms).

Organic dyes can also be made nonfluorescent by inducing reversible changes to the molecule through either cis/trans isomerization [186] and the addition of certain chemical groups [187] or reduction by $\mathrm{NaBH}_{4}$ [188] in a process called photocaging, as seen in Fig. 3civ for a rhodamine dye [189]. Irradiation with the correct wavelength returns the molecule to its fluorescent state $[79,189,190]$. Slow stochastic activation followed by prompt bleaching enables the use of such dyes in SMLM [79, 190].

The novel dye HMSiR represents a class all of its own. This silicon-rhodamine-derived dye naturally resides in a nonfluorescent cyclized form (Fig. 3cvi). It very rarely undergoes a spontaneous change in conformation and becomes fluorescent for a short time. Since this blinking does not require a specialized and probably live-cell-incompatible buffer and is independent of the excitation light intensity, it is very suitable for live-cell imaging [81].

The photochemical properties of individual fluorophores are especially important when designing multicolor experiments. Some fluorescent proteins need specific conditions for proper folding or switching. PAmCherry, for example, requires oxygen for activation, so it cannot be used in oxygen-free buffers [53, 161]. Further, the optimal imaging conditions of a fluorophore partially depend on its redox potential; a buffer that induces blinking in one fluorophore may stabilize another. Table 2 covers most of the working dual- and triple-fluorophore combinations used in SMLM to date.

\section{Super-resolved cell biology}

Direct observations of the molecular processes that take place in cells can help to advance our understanding of life and how the complex interdependencies of single molecules enable it. Using super-resolution microscopy, we can follow these molecules, measure diffusion and progress in assembly processes, and quantify the molecules in subcellular structures at unrivaled spatiotemporal resolution. Over the past decade, rapid developments in these techniques have created a wide spectrum of advanced experimental settings that have already unraveled several mysteries associated with cells, some of which are depicted in Fig. 4 and are briefly summarized below.

\section{Molecular counting and spatial organization}

SMLM data is built on individual single-molecule localizations, and thus allows the absolute stoichiometry of molecules in subcellular structures to be determined.

Here, several effects which compromise this straightforward strategy must be considered. First, undercounting of molecules occurs when some molecules are not counted during the experiment due to, for example, incomplete labeling by the fluorophore, immature or misfolded genetic fluorescent tags, limited photoactivation or switching efficiencies, or insufficient algorithmic registration. The latter problem can be resolved to some degree by using multiemitter fitting algorithms or fluorophore density estimators when there are high fluorescent spot densities, 


\section{a Molecular counting and spatial organization}
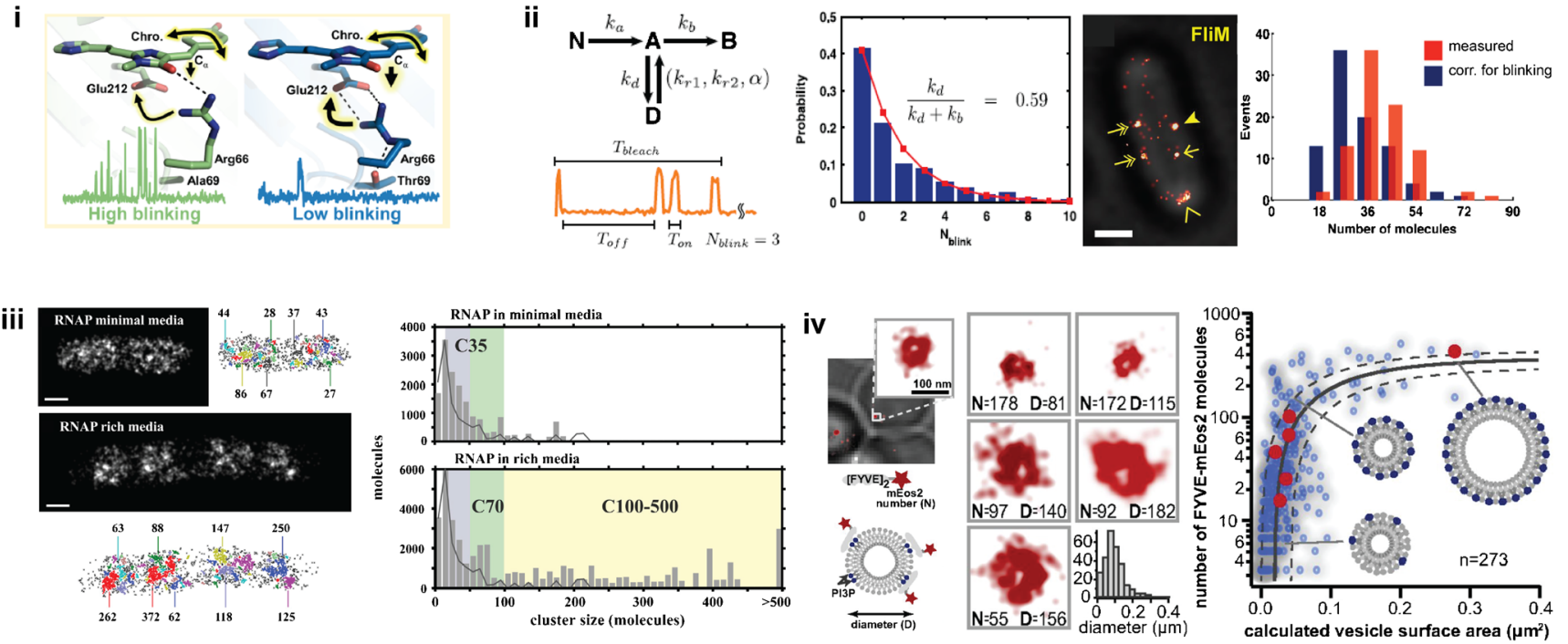

\section{b Cellular multi-component structures}

i
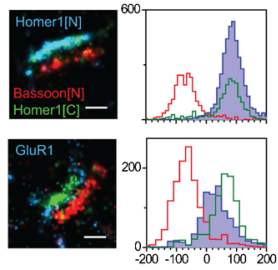

Position $(\mathrm{nm})$
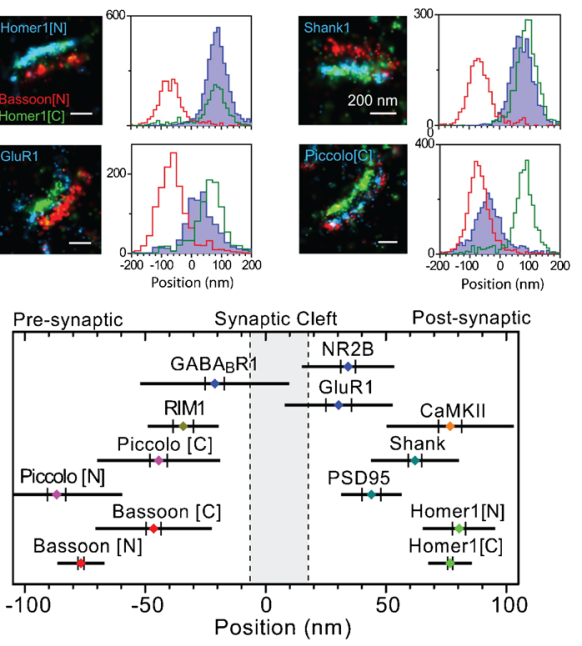

Fig. 4a-b Quantitative super-resolution microscopy. a SMLM allows the stoichiometry of a molecule to be determined, with several over- or undercounting effects taken into account. (i) The photochemical properties of fluorescent proteins lead to specific blinking and bleaching behaviors. The high-blinking and fast-bleaching behaviors shown by mEos2 (left) and Dendra2 (right), respectively, are largely determined by the orientation of the single residue arginine 66. Reprinted with permission from [191]. (ii) Fluorophore blinking behavior can be corrected for using kinetic fluorophore schemes. In this strategy, the number of FliM proteins per flagellar motor is counted in vivo. Reprinted from [192]. (iii) Spatial organization of $E$. coli RNA polymerases under minimal as well as rich growth conditions. Reprinted with permission from [193]. (iv) Maturation of endocytic vesicles into late endosomes. Reprinted from [194]. (b)

thus decreasing the number of missed localizations [43]. Second, overcounting effects can occur when localized local background fluctuations lead to falsely included positions, during multiple target counting by multiple

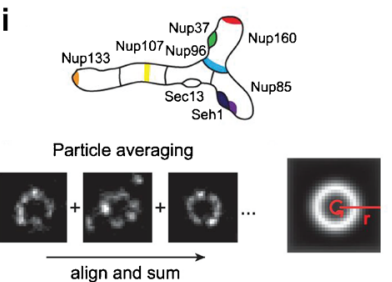

iii

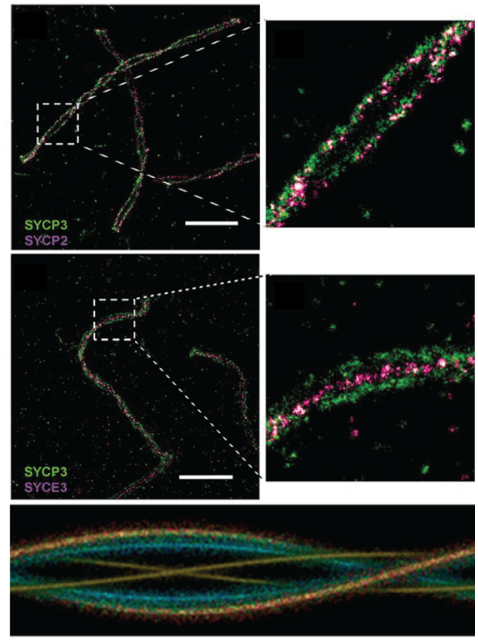

Structural super-resolution microscopy reveals the molecular architecture of cellular multicomponent complexes. (i) Mutual organization of various pre- and postsynaptic proteins in relation to the proteins Bassoon and Homer1. Reprinted with permission from [139]. (ii) Combining data from identical particles yields a high-resolution average. Systematic SMLM imaging of the Y-shaped subunit of the nuclear pore complex allows it to be aligned onto the electron density of the nuclear pore (bottom). Reprinted with permission from [104]. (iii) Aligning different pairs of synaptonemal proteins onto a helical template yields the threedimensional model of the synaptonemal complex with isotropic resolution. Reprinted from [105]. Scale bars: a aii and aiii $500 \mathrm{~nm}$; aiv $100 \mathrm{~nm} ; \mathbf{b} i$ $200 \mathrm{~nm}$; biii $2 \mu \mathrm{m}$

antibodies or multiple fluorescent labels, or due to multiple localizations per fluorophore caused by blinking behavior. Uncorrected SMLM data can thus result in apparent self-clustering of localizations, which tends to be 
misinterpreted as clustered organization of the target molecule. These effects can be reduced by, for example, using a fast-maturing one-to-one endogenous fluorescent protein fusion with (engineered) low-blinking behavior. Recently, a mechanistic study revealed that the side-chain conformation of arginine 66 seen in Fig. 4ai is sufficient to cause the popular fluorophores mEos2 (left) and Dendra2 (right) to either blink or bleach, respectively. Consequently, the engineered single mutants mEos2-A69T and Dendra2-T69A show completely swapped behaviors [191].

To further account for miscounting effects, SMLM localizations can be tracked for fluorescent emissions spanning several imaging frames, weighted by known fluorophore detection efficiencies, and statistically corrected for fluorophore blinking [192, 194-196]. For example, as seen in Fig. 4aii, Lee et al. introduced kinetic fluorophore models and accessed the blinking probability of the fluorescent protein tag in order to then count 33 molecules of FliM protein per bacterial flagellar motor in vivo [192]. Further, the varying spatial organization of DNA transcribing E. coli RNA polymerase for different metabolic conditions (Fig. 4aiii) as well as the maturation pathway of small endocytic vesicles which form at the membrane and then develop into late endosomes in yeast (Fig. 4aiv) have been revealed.

\section{Cellular multicomponent structures}

Using super-resolution methods, not only can individual molecules be precisely localized, but the large molecular architecture of multiprotein complexes and whole organelles as well as the organization of the genome or membrane can be targeted in the native cellular environment. This yields detailed quantitative molecular maps that capture these large assemblies and place hundreds of different molecules into assembled three-dimensional structures while maintaining the high spatiotemporal resolution of the method. These structures, such as the synapse depicted in Fig. 4bi, can allow us to advance our molecular understanding of their functions and reveal large-scale cellular organization. In the study shown in Fig. 4bi, various pre- and postsynaptic proteins were imaged in relation to the $\mathrm{N}$-terminal localization of the protein Bassoon and the C-terminus of Homer1 by triple-color SMLM, which elucidated their mutual organization in proximity to the synaptic cleft. Indeed, the macromolecular assemblies studied so far using super-resolution techniques comprise an impressive list, including the nuclear pore complex, the ESCRT transport machinery, the neuronal architecture, focal adhesions, the centrosome and cellular division, the endocytosis pathway, as well as the organization of chromatin and membrane lipid domains (see the detailed review in [197]).
Averaging the data for super-resolved identical particles involves combining the individual copies of the same structure into a high-resolution average that complements the single images. This is useful because a single image may have some information missing due to absent affinity labels, imperfect photoswitching of the fluorophores, or nonisotropic resolution. Such a particle averaging strategy can help to elucidate the compositions and organization of macromolecular structures; for instance, the organization of the Y-shaped nuclear pore complex (NPC) subunit Nup107-160 was retrieved and matched with the electron density of the cytoplasmic ring of the nuclear pore via systematic two-dimensional SMLM imaging (Fig. 4bii) [104]. Aligning two-color and two-dimensional SMLM data from different pairs of synaptonemal proteins onto a helical template yielded a three-dimensional model of the synaptonemal complex with isotropic resolution (Fig. 4biii) [105]. The centrosomes of Drosophila [198], yeast [199], and humans [200] were studied by combining threedimensional SIM images. Thus, super-resolution microscopy combined with particle averaging complements current structural biology studies, as it can target structures that are too large for cryoelectron microscopy or when preparation for X-ray crystallography fails. In this context, techniques like subtomogram averaging [201] adapted for three-dimensional super-resolution microscopy could allow us to resolve even more structures at higher in situ resolution, and correlative interaction networks combining super-resolved data with other (e.g., biochemical or genetic) analyzes could lead to large systems biology approaches, which could further refine current studies.

\section{Live-cell imaging}

Fluorescence microscopy plays a key role in revealing the structures and functions of living cells in a minimally invasive manner through the use of genetic tags, and thus profits greatly from efficient genome engineering, such as the developing CRISPR-Cas technique [202]. For example, by applying STED microscopy to the visual cortex of YFP-transgenic and anesthetized (but live) mice, it has been possible to observe fine details and measure the dynamics of the tiny dendritic spines in vivo (Fig. 5ai) [203]. In order to improve livecell super-resolution microscopy strategies, new designs are mainly focusing on three goals: accelerating the imaging speed, lowering the phototoxicity, and expanding the field of view in the lateral as well as vertical directions, all without compromising the resolution. The most critical issues to address are the laser intensities and imaging times used, which, depending on the wavelength of the laser and the irradiation dose, can compromise the health of the cells being studied $[141,207,208]$. Possible solutions involve developing new fast switching fluorophores that can be applied at lower laser 
a Live cell imaging
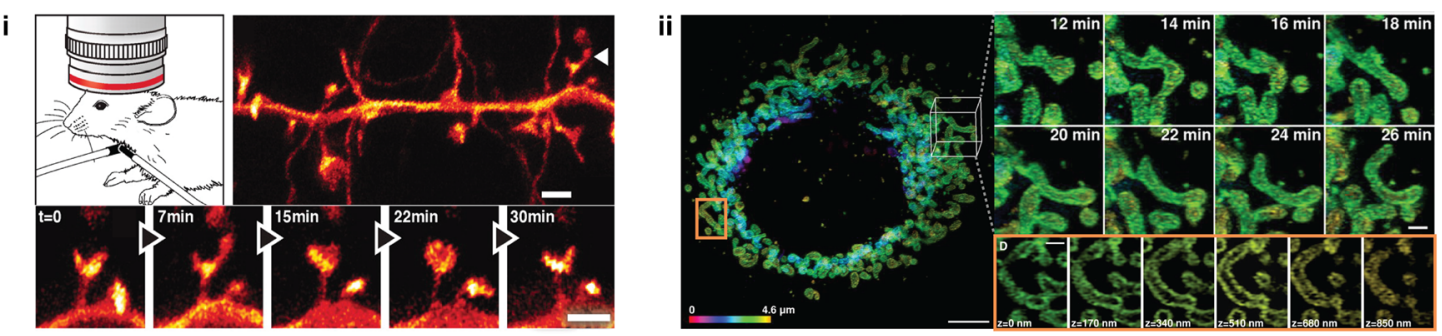

\section{b Molecular diffusion dynamics}
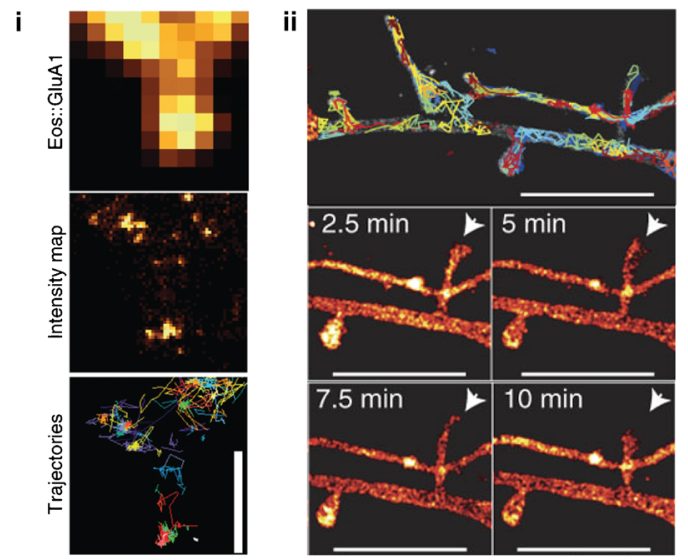

iii
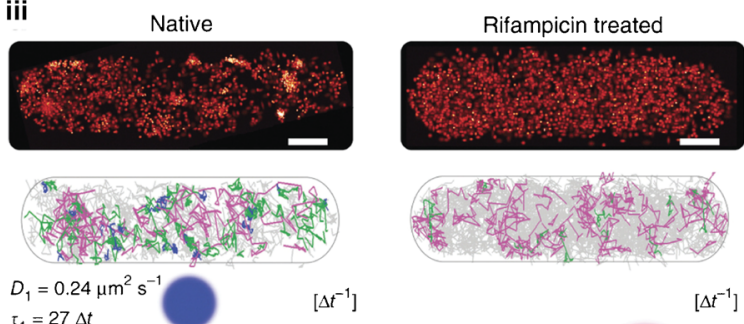

$\tau_{1}=27 \Delta$
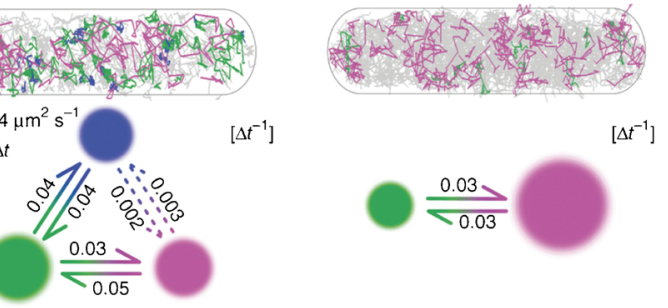

$D_{2}=0.75 \mu \mathrm{m}^{2} \mathrm{~s}^{-1} \quad D_{3}=2.6 \mu \mathrm{m}^{2} \mathrm{~s}^{-1}$

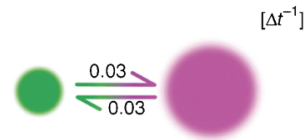

$\tau_{2}=14 \Delta t \quad \tau_{3}=19 \Delta$

$D_{1}=0.71 \mu \mathrm{m}^{2} \mathrm{~s}^{-1} \quad D_{2}=3.1 \mu \mathrm{m}^{2} \mathrm{~s}^{-1}$

$\tau_{1}=32 \Delta t \quad \tau_{2}=38 \Delta t$

\section{c Correlative microscopy}
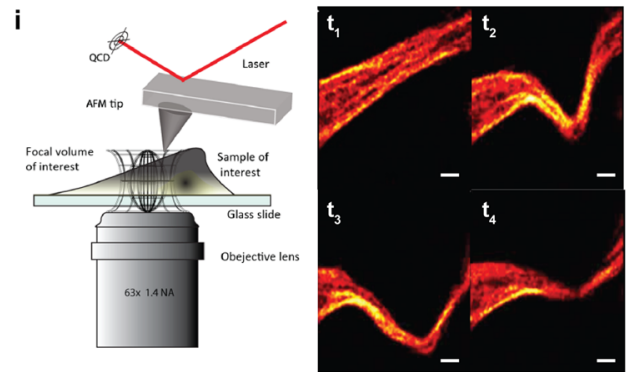

Fig. 5a-c Advanced dynamic and correlative super-resolution microscopy approaches. a Live imaging has been successfully performed on living cells and mammals. (i) STED microscopy of the dynamics of dendritic spines (arrows) in the visual cortex of living, YFP-transgenic, anesthetized mouse. Reprinted with permission from [203]. (ii) Mitochondrial fusion and fission dynamics imaged over a period of several tens of minutes by nonlinear SIM in lattice light sheet configuration. Reprinted with permission from [13]. b Single-particle tracking schemes elucidate molecular diffusional dynamics. (i) High-density tracking of AMPA receptors reveals confined nanodomains in the postsynaptic regions. Reprinted with permission from [204]. (ii) In contrast, membranebound GPI demonstrates a more homogeneous diffusion. Reprinted with permission from [4]. (iii) Bayesian hidden Markov model assessment of

irradiations; fluorescent proteins that are usable in the longer (less toxic) near-infrared wavelength range, thus permitting deep-tissue imaging; as well as protected dyes that are shielded from the environment, similar to a fluorescent protein barrel. Such a protective structure could then also shield the

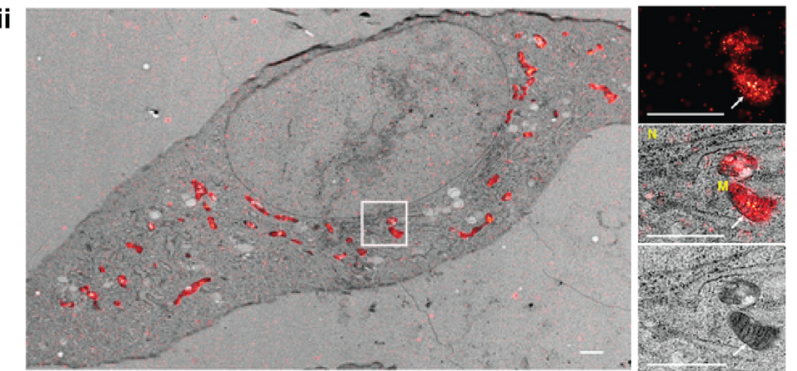

Hfq protein dynamics in E. coli cells. When mRNA synthesis is inhibited, the fraction of Hfq-binding mRNA (state of slowest diffusion) disappears. Reprinted with permission from [205]. c Correlative microscopy allows diverse features of a sample to be measured. (i) STED microscopy combined with atomic force microscopy (AFM) visualizes the response of the cytoskeleton upon nanomanipulation by the AFM tip. Reprinted with permission from [206]. (ii) Correlative PALM and electron microscopy of the mitochondrially targeted fluorescent protein mEos 4 verifies its intact photoconversion and fluorescence under heavy osmium tetroxide fixation. Reprinted by permission from [114]. Scales: ai $1 \mu \mathrm{m}$; aii $5 \mu \mathrm{m}$ (left) and $1 \mu \mathrm{m}$ (right); bi $800 \mathrm{~nm}$; bii $2 \mu \mathrm{m}$; biii $500 \mathrm{~nm}$; c $i 2 \mu \mathrm{m}$, cii $1 \mu \mathrm{m}$

cell from ROS and free radicals originating from photochemical reactions in the proximity of the chromophore during excitational or switching processes. New technical implementations which optimize the use of the limited photon budget per fluorophore as well as the imaging speed are 
favored, such as methods which confine but also parallelize the imaging by multifocal or lattice-like excitation or allow for multifocal detection [209-212]. New rapid and large sCMOS detectors increase the observation volume and allow for faster SMLM switching [3].

During the last few years it has therefore become possible to image whole living cells and organisms over longer timescales. One recent implementation of various types of SIM designs is a three-dimensional nonlinear SIM developed by $\mathrm{Li}$ et al. that uses photoswitchable fluorophores combined with lattice-lightsheet microscopy to show endocytic and cytoskeletal dynamics as well as the fission and fusion of mitochondria of whole live cells by labeling their membranes. They resolved the intracellular dynamics at individual mitochondrial constrictions over a period of several tens of minutes at a resolution of about $45 \mathrm{~nm}$ laterally and $170 \mathrm{~nm}$ vertically (Fig. 5aii) [13].

Another technical advance that is currently being explored is the implementation of adaptive optics to correct for aberrations in large sample volumes, e.g., multicellular organisms [213]. All three-dimensional localization microscopy algorithms have been challenged to participate in a large assessment, in order to evaluate their performance and identify common limitations on them. The results should ultimately guide development work aimed at optimizing three-dimensional SMLM resolution when studying protein ultrastructure in vivo [214].

\section{Following molecule diffusion dynamics}

Single-particle tracking schemes directly monitor the kinetics of intracellular processes. In combination with photoactivatable fluorescent proteins in sptPALM, it is possible to follow the diffusion of individual proteins on cell membranes as well as in the cytoplasm of living cells, and to measure thousands of short single-molecule trajectories by sequential photoactivation. High-density tracking of the GluA1 subunits of AMPA receptors in the membranes of dendritic spines of live hippocampal neurons has revealed their discrete organization in 70-100 $\mathrm{nm}$ diameter nanodomains, and has shown that the receptors are mainly immobilized in the postsynapse (Fig. 5bi) [204], in contrast to the membrane-anchored glycosylphosphatidylinositolGFP (Fig. 5bii). It is also possible to classify individual trajectories by their apparent diffusion constant into distinct states of diffusion, corresponding, for example, to different states of binding. This allows spatial and temporal heterogeneities in protein properties to be resolved. These are normally hidden in ensemble averages but are highly valuable when used in mathematical models for systems biology: by performing Bayesian assessments of hidden Markov models that combine the information from all short trajectories, it has recently been shown that the diffusion constants and state transition rates as well as the number of states in the model can be extracted [205]. This approach has been tested for the protein $\mathrm{Hfq}$ in $E$. coli, which mediates posttranscriptional gene regulation by facilitating interactions between mRNA and noncoding small RNA. The Hfq dynamics are highly altered when transcription is blocked using the drug rifampicin, as this decreases the mRNA level in the cell. The state with the slowest diffusion-most likely Hfq binding to the mRNA being transcribed-disappears, and the fraction occupying the intermediate state decreases substantially (Fig. 5biii).

\section{Correlative microscopy}

Correlative microscopy combines the advantages of and opportunities provided by different methods, and thus allows different features of the exact same sample to be measured. For instance, a correlative approach can combine dynamic tracking studies with structural imaging when mapping intracellular vesicle transport on the cytoskeleton [71]. Also possible is the real-time visualization of the fast responses of the cytoskeleton of HeLa cells upon physical nanomanipulation by an atomic force microscopy tip in correlative STED microscopy (Fig. 5ci) [206]. Another direction in correlative imaging is to combine the high ultrastructural resolution and cellular context information of electron microscopy with the specific localization of molecules in super-resolution microscopy (Fig. 5cii) [215]. Unfortunately, most current correlative schemes still suffer from complex and tedious fixation protocols as well as limited labeling and imaging strategies, i.e., the cryo- or resin-covered environments used for electron microscopy impair the photophysics of most standard fluorophores. However, technical implementations develop rapidly; for instance, a correlative fluorescent protein tag, mEos4, which fluoresces and photoconverts normally under heavy osmium tetroxide fixation has recently been developed (Fig. 5c, ii) [114], and the dye TMR has been shown to not only preserve its fluorescence during high-pressure freezing and freeze substitution preparations, but to be able to photooxidize diaminobenzidine (DAB) too, which then yields high electronmicroscopic contrast $[173,216]$.

In an optimistic but still realistic future, superresolution microscopy will push beyond its current limits of routinely achieving experimental resolutions of tens of nanometers to approach the distances of typical singlemolecule FRET measurements $(2-10 \mathrm{~nm})$ as well as the structural resolution of cryoelectron microscopy and Xray crystallography (about $2-3 \AA$ ), which will allow us to more directly combine the heterogeneity and dynamics of protein complexes measured in vivo with the precise structural information available from purified protein complexes. 


\section{Outlook}

Over the last few decades, super-resolution microscopy has proven its value in the life sciences, and a myriad of biological applications of super-resolution microscopy have emerged. The super-resolution toolbox currently consists of many diverse methods and application strategies that complement traditional cell biology studies as well as techniques from molecular biology or biochemistry. Super-resolution microscopy is on its way to becoming a standard research tool, which is leading to a huge demand for computer-based data processing and openly available analysis software for (advanced) data evaluation, visualization, and comparison, as well as accessible, affordable, and simple-to-use hardware implementations. Also, superresolution microscopy traditionally yields large volumes of microscopic data, which would ideally be stored and handled in open-access public platforms. Whether this vision comes to pass largely depends on the development of new algorithms as well as open-source software and strategies for efficient large-scale data handling.

Acknowledgments Open access funding provided by Max Planck Society.

\section{Compliance with ethical standards}

Conflicts of interest The authors declare that they have no conflict of interest.

Open Access This article is distributed under the terms of the Creative Commons Attribution 4.0 International License (http:// creativecommons.org/licenses/by/4.0/), which permits unrestricted use, distribution, and reproduction in any medium, provided you give appropriate credit to the original author(s) and the source, provide a link to the Creative Commons license, and indicate if changes were made.

\section{References}

1. Liu Z, Lavis LD, Betzig E. Imaging live-cell dynamics and structure at the single-molecule level. Mol Cell. 2015;58(4):644-59. doi:10.1016/j.molcel.2015.02.033.

2. Hell SW, Sahl SJ, Bates M, Zhuang XW, Heintzmann R, Booth MJ et al. The 2015 super-resolution microscopy roadmap. J Phys D Appl Phys. 2015;48(44). doi:10.1088/0022-3727/48/44/443001.

3. Winter PW, Shroff H. Faster fluorescence microscopy: advances in high speed biological imaging. Curr Opin Chem Biol. 2014;20: 46-53. doi:10.1016/j.cbpa.2014.04.008.

4. Ries J, Kaplan C, Platonova E, Eghlidi H, Ewers H. A simple, versatile method for GFP-based super-resolution microscopy via nanobodies. Nat Methods. 2012;9(6):582-4. doi:10.1038/nmeth.1991.

5. Vreja IC, Nikic I, Gottfert F, Bates M, Krohnert K, Outeiro TF, et al. Super-resolution microscopy of clickable amino acids reveals the effects of fluorescent protein tagging on protein assemblies. ACS Nano. 2015;9(11):11034-41. doi:10.1021/acsnano.5 b04434.

6. Klar TA, Hell SW. Subdiffraction resolution in far-field fluorescence microscopy. Opt Lett. 1999;24(14):954-6.
7. Gustafsson MG. Surpassing the lateral resolution limit by a factor of two using structured illumination microscopy. J Microsc. 2000;198(Pt 2):82-7.

8. Betzig E, Patterson GH, Sougrat R, Lindwasser OW, Olenych S, Bonifacino JS, et al. Imaging intracellular fluorescent proteins at nanometer resolution. Science. 2006;313(5793):1642-5. doi:10.1126/science.1127344.

9. Rust MJ, Bates M, Zhuang X. Sub-diffraction-limit imaging by stochastic optical reconstruction microscopy (STORM). Nat Methods. 2006;3(10):793-5. doi:10.1038/nmeth929.

10. Heilemann M, van de Linde S, Schuttpelz M, Kasper R, Seefeldt B, Mukherjee A, et al. Subdiffraction-resolution fluorescence imaging with conventional fluorescent probes. Angew Chem Int Ed. 2008;47(33):6172-6. doi:10.1002/anie.200802376.

11. Kner P, Chhun BB, Griffis ER, Winoto L, Gustafsson MGL. Superresolution video microscopy of live cells by structured illumination. Nat Methods. 2009;6(5):339-42. doi:10.1038/nmeth.1324.

12. Gustafsson MG, Shao L, Carlton PM, Wang CJ, Golubovskaya IN, Cande WZ, et al. Three-dimensional resolution doubling in wide-field fluorescence microscopy by structured illumination. Biophys J. 2008;94(12):4957-70. doi:10.1529/biophysj.107.120345.

13. Li D, Shao L, Chen BC, Zhang X, Zhang M, Moses B, et al. Extended-resolution structured illumination imaging of endocytic and cytoskeletal dynamics. Science. 2015;349(6251), aab3500. doi:10.1126/science.aab3500.

14. Bückers J, Wildanger D, Vicidomini G, Kastrup L, Hell SW. Simultaneous multi-lifetime multi-color STED imaging for colocalization analyses. Opt Express. 2011;19(4):3130-43. doi:10.1364/OE.19.003130.

15. Xu K, Babcock HP, Zhuang X. Dual-objective STORM reveals three-dimensional filament organization in the actin cytoskeleton. Nat Methods. 2012;9(2):185-8.

16. Rayleigh XV. On the theory of optical images, with special reference to the microscope. Philos Mag. 1896;42(255):167-95. doi:10.1080/14786449608620902.

17. Siedentopf H, Zsigmondy R. Über Sichtbarmachung und Größenbestimmung ultramikoskopischer Teilchen, mit besonderer Anwendung auf Goldrubingläser. Ann Phys. 1902;315(1):1-39. doi:10.1002/andp.19023150102.

18. König K. Multiphoton microscopy in life sciences. J Microsc. 2000;200(2):83-104. doi:10.1046/j.1365-2818.2000.00738.x.

19. Betzig E, Lewis A, Harootunian A, Isaacson M, Kratschmer E. Near field scanning optical microscopy (NSOM): development and biophysical applications. Biophys J. 1986;49(1):269-79. doi:10.1016/S0006-3495(86)83640-2.

20. Harke B, Keller J, Ullal CK, Westphal V, Schonle A, Hell SW. Resolution scaling in STED microscopy. Opt Express. 2008;16(6):4154-62.

21. Schmidt R, Wurm CA, Jakobs S, Engelhardt J, Egner A, Hell SW. Spherical nanosized focal spot unravels the interior of cells. Nat Methods. 2008;5(6):539-44. doi:10.1038/nmeth.1214.

22. Willig KI, Harke B, Medda R, Hell SW. STED microscopy with continuous wave beams. Nat Methods. 2007;4(11):915-8. doi:10.1038/nmeth1108.

23. Vicidomini G, Moneron G, Han KY, Westphal V, Ta H, Reuss M, et al. Sharper low-power STED nanoscopy by time gating. Nat Methods. 2011;8(7):571-3. doi:10.1038/nmeth.1624.

24. Staudt T, Engler A, Rittweger E, Harke B, Engelhardt J, Hell SW. Farfield optical nanoscopy with reduced number of state transition cycles. Opt Express. 2011;19(6):5644-57. doi:10.1364/OE.19.005644.

25. Grotjohann T, Testa I, Leutenegger M, Bock H, Urban NT, Lavoie-Cardinal F, et al. Diffraction-unlimited all-optical imaging and writing with a photochromic GFP. Nature. 2011;478(7368): 204-8. doi:10.1038/nature10497.

26. Danzl JG, Sidenstein SC, Gregor C, Urban NT, Ilgen P, Jakobs $\mathrm{S}$, et al. Coordinate-targeted fluorescence nanoscopy 
with multiple off states. Nat Photonics. 2016;10(2):122-8. doi:10.1038/nphoton.2015.266.

27. Eggeling C, Willig KI, Barrantes FJ. STED microscopy of living cells-new frontiers in membrane and neurobiology. J Neurochem. 2013;126(2):203-12. doi:10.1111/jnc.12243.

28. Donnert G, Keller J, Wurm CA, Rizzoli SO, Westphal V, Schönle A, et al. Two-color far-field fluorescence nanoscopy. Biophys J. 2007;92(8):L67-9. doi:10.1529/biophysj.107.104497.

29. Gottfert F, Wurm CA, Mueller V, Berning S, Cordes VC, Honigmann A, et al. Coaligned dual-channel STED nanoscopy and molecular diffusion analysis at $20 \mathrm{~nm}$ resolution. Biophys J. 2013;105(1):L01-3. doi:10.1016/j.bpj.2013.05.029.

30. Tonnesen J, Nadrigny F, Willig KI, Wedlich-Soldner R, Nagerl UV. Two-color STED microscopy of living synapses using a single laser-beam pair. Biophys J. 2011;101(10):2545-52. doi:10.1016/j.bpj.2011.10.011

31. Willig KI, Stiel AC, Brakemann T, Jakobs S, Hell SW. Dual-label STED nanoscopy of living cells using photochromism. Nano Lett. 2011;11(9):3970-3. doi:10.1021/n1202290w.

32. Jost A, Heintzmann R. Superresolution multidimensional imaging with structured illumination microscopy. Annu Rev Mater Res. 2013;43(1):261-82. doi:10.1146/annurev-matsci-071312121648 .

33. Ball G, Demmerle J, Kaufmann R, Davis I, Dobbie IM, Schermelleh L. SIMcheck: a toolbox for successful superresolution structured illumination microscopy. Sci Rep. 2015;5: 15915. doi:10.1038/srep15915.

34. Muller M, Monkemoller V, Hennig S, Hubner W, Huser T. Opensource image reconstruction of super-resolution structured illumination microscopy data in ImageJ. Nat Commun. 2016;7:10980. doi:10.1038/ncomms 10980 .

35. Hirvonen LM, Wicker K, Mandula O, Heintzmann R. Structured illumination microscopy of a living cell. Eur Biophys J. 2009;38(6):807-12. doi:10.1007/s00249-009-0501-6.

36. York AG, Parekh SH, Dalle Nogare D, Fischer RS, Temprine K, Mione M, et al. Resolution doubling in live, multicellular organisms via multifocal structured illumination microscopy. Nat Methods. 2012;9(7):749-54. doi:10.1038/nmeth.2025.

37. Schermelleh L, Carlton PM, Haase S, Shao L, Winoto L, Kner P, et al. Subdiffraction multicolor imaging of the nuclear periphery with 3D structured illumination microscopy. Science. 2008;320(5881):1332-6. doi:10.1126/science.1156947.

38. Schaefer LH, Schuster D, Schaffer J. Structured illumination microscopy: artefact analysis and reduction utilizing a parameter optimization approach. J Microsc. 2004;216(2):165-74. doi:10.1111/j.0022-2720.2004.01411.x.

39. Gustafsson MG. Nonlinear structured-illumination microscopy: wide-field fluorescence imaging with theoretically unlimited resolution. Proc Natl Acad Sci USA. 2005;102(37):13081-6. doi:10.1073/pnas.0406877102.

40. Rego EH, Shao L, Macklin JJ, Winoto L, Johansson GA, KampsHughes $\mathrm{N}$, et al. Nonlinear structured-illumination microscopy with a photoswitchable protein reveals cellular structures at 50nm resolution. Proc Natl Acad Sci USA. 2012;109(3):E135-43. doi:10.1073/pnas.1107547108.

41. Fölling J, Bossi M, Bock H, Medda R, Wurm CA, Hein B, et al. Fluorescence nanoscopy by ground-state depletion and singlemolecule return. Nat Methods. 2008;5(11):943-5.

42. Moerner WE. Microscopy beyond the diffraction limit using actively controlled single molecules. J Microsc. 2012;246(3):21320. doi:10.1111/j.1365-2818.2012.03600.x.

43. Small A, Stahlheber S. Fluorophore localization algorithms for super-resolution microscopy. Nat Methods. 2014;11(3):267-79. doi:10.1038/nmeth.2844.

44. Sage D, Kirshner H, Pengo T, Stuurman N, Min J, Manley S, et al. Quantitative evaluation of software packages for single-molecule localization microscopy. Nat Methods. 2015;12(8):717-24. doi:10.1038/nmeth.3442.

45. Chenouard N, Smal I, de Chaumont F, Maska M, Sbalzarini IF, Gong Y, et al. Objective comparison of particle tracking methods. Nat Methods. 2014;11(3):281-9. doi:10.1038/nmeth.2808.

46. Thompson RE, Larson DR, Webb WW. Precise nanometer localization analysis for individual fluorescent probes. Biophys J. 2002;82(5):2775-83.

47. Axelrod D. Total internal reflection fluorescence microscopy in cell biology. Methods Enzymol. 2003;361:1-33.

48. Tokunaga M, Imamoto N, Sakata-Sogawa K. Highly inclined thin illumination enables clear single-molecule imaging in cells. Nat Methods. 2008;5(2):159-61. doi:10.1038/nmeth1171.

49. York AG, Ghitani A, Vaziri A, Davidson MW, Shroff H. Confined activation and subdiffractive localization enables whole-cell PALM with genetically expressed probes. Nat Methods. 2011;8(4):327-33.

50. Cella Zanacchi F, Lavagnino Z, Perrone Donnorso M, Del Bue A, Furia L, Faretta M, et al. Live-cell 3D super-resolution imaging in thick biological samples. Nat Methods. 2011;8(12):1047-9.

51. Chen BC, Legant WR, Wang K, Shao L, Milkie DE, Davidson MW, et al. Lattice light-sheet microscopy: imaging molecules to embryos at high spatiotemporal resolution. Science. 2014;346(6208):1257998. doi:10.1126/science.1257998.

52. van de Linde S, Endesfelder U, Mukherjee A, Schuttpelz M, Wiebusch G, Wolter S, et al. Multicolor photoswitching microscopy for subdiffraction-resolution fluorescence imaging. Photochem Photobiol Sci. 2009;8(4):465-9. doi:10.1039/B822533H.

53. Endesfelder U, Malkusch S, Flottmann B, Mondry J, Liguzinski P, Verveer PJ, et al. Chemically induced photoswitching of fluorescent probes - a general concept for super-resolution microscopy. Molecules. 2011;16(4):3106.

54. Laine RF, Albecka A, van de Linde S, Rees EJ, Crump CM, Kaminski CF. Structural analysis of herpes simplex virus by optical super-resolution imaging. Nat Commun. 2015;6. doi:10.1038/ncomms6980.

55. Testa I, Wurm CA, Medda R, Rothermel E, von Middendorf C, Fölling J, et al. Multicolor fluorescence nanoscopy in fixed and living cells by exciting conventional fluorophores with a single wavelength. Biophys J. 2010;99(8):2686-94. doi:10.1016/j. bpj.2010.08.012.

56. Shroff H, Galbraith CG, Galbraith JA, White H, Gillette J, Olenych $\mathrm{S}$, et al. Dual-color superresolution imaging of genetically expressed probes within individual adhesion complexes. Proc Natl Acad Sci USA. 2007;104(51):20308-13. doi:10.1073/pnas.0710517105.

57. Grimm JB, Klein T, Kopek BG, Shtengel G, Hess HF, Sauer M, et al. Synthesis of a far-red photoactivatable silicon-containing rhodamine for super-resolution microscopy. Angew Chem Int Ed. 2016;55(5):1723-7. doi:10.1002/anie.201509649.

58. Bates M, Huang B, Dempsey GT, Zhuang X. Multicolor superresolution imaging with photo-switchable fluorescent probes. Science. 2007;317(5845):1749-53. doi:10.1126/science.1146598.

59. Subach FV, Patterson GH, Manley S, Gillette JM, LippincottSchwartz J, Verkhusha VV. Photoactivatable mCherry for highresolution two-color fluorescence microscopy. Nat Methods. 2009;6(2):153-9.

60. Gunewardene Mudalige S, Subach Fedor V, Gould Travis J, Penoncello Gregory P, Gudheti Manasa V, Verkhusha Vladislav $\mathrm{V}$, et al. Superresolution imaging of multiple fluorescent proteins with highly overlapping emission spectra in living cells. Biophys J. 2011;101(6):1522-8. doi:10.1016/j.bpj.2011.07.049.

61. Lampe A, Haucke V, Sigrist SJ, Heilemann M, Schmoranzer J. Multi-colour direct STORM with red emitting carbocyanines. Biol Cell. 2012;104(4):229-37. doi:10.1111/boc.201100011.

62. Zhang Z, Kenny SJ, Hauser M, Li W, Xu K. Ultrahigh-throughput single-molecule spectroscopy and spectrally resolved super- 
resolution microscopy. Nat Methods. 2015;12(10):935-8. doi:10.1038/nmeth.3528.

63. Lehmann M, Lichtner G, Klenz H, Schmoranzer J. Novel organic dyes for multicolor localization-based super-resolution microscopy. J Biophotonics. 2016;9(1-2):161-70. doi:10.1002/jbio.201500119.

64. Biteen JS, Thompson MA, Tselentis NK, Bowman GR, Shapiro L, Moerner WE. Super-resolution imaging in live Caulobacter crescentus cells using photoswitchable EYFP. Nat Methods. 2008;5(11):947-9.

65. Wombacher R, Heidbreder M, van de Linde S, Sheetz MP, Heilemann M, Cornish VW, et al. Live-cell super-resolution imaging with trimethoprim conjugates. Nat Methods. 2010;7(9):717-9.

66. Jones SA, Shim S-H, He J, Zhuang X. Fast, three-dimensional super-resolution imaging of live cells. Nat Methods. 2011;8(6): 499-505.

67. Manley S, Gillette JM, Patterson GH, Shroff H, Hess HF, Betzig E, et al. High-density mapping of single-molecule trajectories with photoactivated localization microscopy. Nat Methods. 2008;5(2): 155-7.

68. Frost NA, Shroff H, Kong H, Betzig E, Blanpied TA. Singlemolecule discrimination of discrete perisynaptic and distributed sites of actin filament assembly within dendritic spines. Neuron. 2010;67(1):86-99. doi:10.1016/j.neuron.2010.05.026.

69. Rossier O, Octeau V, Sibarita J-B, Leduc C, Tessier B, Nair D, et al. Integrins $\beta 1$ and $\beta 3$ exhibit distinct dynamic nanoscale organizations inside focal adhesions. Nat Cell Biol. 2012;14(10):1057-67.

70. Sanamrad A, Persson F, Lundius EG, Fange D, Gynnå AH, Elf J. Single-particle tracking reveals that free ribosomal subunits are not excluded from the Escherichia coli nucleoid. Proc Natl Acad Sci USA. 2014;111(31):11413-8. doi:10.1073/pnas.1411558111.

71. Bálint Š, Verdeny Vilanova I, Sandoval Álvarez Á, Lakadamyali M. Correlative live-cell and superresolution microscopy reveals cargo transport dynamics at microtubule intersections. Proc Natl Acad Sci USA. 2013;110(9):3375-80. doi:10.1073/pnas.1219206110.

72. Klehs K, Spahn C, Endesfelder U, Lee SF, Furstenberg A, Heilemann $\mathrm{M}$. Increasing the brightness of cyanine fluorophores for singlemolecule and superresolution imaging. ChemPhysChem. 2014;15(4):637-41. doi:10.1002/cphc.201300874.

73. Zheng Q, Jockusch S, Zhou Z, Altman RB, Warren JD, Turro NJ, et al. On the mechanisms of cyanine fluorophore photostabilization. J Phys Chem Lett. 2012;3(16):2200-3. doi:10.1021/jz300670p.

74. Vogelsang J, Kasper R, Steinhauer C, Person B, Heilemann M, Sauer $\mathrm{M}$, et al. A reducing and oxidizing system minimizes photobleaching and blinking of fluorescent dyes. Angew Chem Int Ed. 2008;47(29):5465-9. doi:10.1002/anie.200801518.

75. van de Linde S, Krstic I, Prisner T, Doose S, Heilemann M, Sauer M. Photoinduced formation of reversible dye radicals and their impact on super-resolution imaging. Photochem Photobiol Sci. 2011;10(4):499-506. doi:10.1039/c0pp00317d.

76. Henderson JN, Gepshtein R, Heenan JR, Kallio K, Huppert D, Remington SJ. Structure and mechanism of the photoactivatable green fluorescent protein. J Am Chem Soc. 2009;131(12):4176-7.

77. McKinney SA, Murphy CS, Hazelwood KL, Davidson MW, Looger LL. A bright and photostable photoconvertible fluorescent protein. Nat Methods. 2009;6(2):131-3. doi:10.1038/nmeth.1296.

78. Habuchi S, Dedecker P, Hotta J-i, Flors C, Ando R, Mizuno $\mathrm{H}$, et al. Photo-induced protonation/deprotonation in the GFP-like fluorescent protein Dronpa: mechanism responsible for the reversible photoswitching. Photochem Photobiol Sci. 2006;5(6):567-76.

79. Banala S, Maurel D, Manley S, Johnsson K. A caged, localizable rhodamine derivative for superresolution microscopy. ACS Chem Biol. 2011;7(2):289-93.
80. Dempsey GT, Bates M, Kowtoniuk WE, Liu DR, Tsien RY, Zhuang X. Photoswitching mechanism of cyanine dyes. J Am Chem Soc. 2009;131(51):18192-3. doi:10.1021/ja904588g.

81. Uno SN, Kamiya M, Yoshihara T, Sugawara K, Okabe K, Tarhan $\mathrm{MC}$, et al. A spontaneously blinking fluorophore based on intramolecular spirocyclization for live-cell super-resolution imaging. Nat Chem. 2014;6(8):681-9. doi:10.1038/nchem.2002.

82. Lakowicz JR. Principles of fluorescence spectroscopy. New York: Springer; 2013.

83. Klessinger M. Konstitution und Lichtabsorption organischer Farbstoffe. Chem Unserer Zeit. 1978;12(1):1-11. doi:10.1002/ciuz.19780120102.

84. Sinha RP, Häder D-P. UV-induced DNA damage and repair: a review. Photochem Photobiol Sci. 2002;1(4):225-36.

85. Aubin JE. Autofluorescence of viable cultured mammalian cells. J Histochem Cytochem. 1979;27(1):36-43. doi:10.1177/27.1.220325.

86. DeRosa MC, Crutchley RJ. Photosensitized singlet oxygen and its applications. Coord Chem Rev. 2002;233:351-71.

87. D'Este E, Kamin D, Göttfert F, El-Hady A, Hell Stefan W. STED nanoscopy reveals the ubiquity of subcortical cytoskeleton periodicity in living neurons. Cell Rep. 2015;10(8):1246-51. doi:10.1016/j.celrep.2015.02.007.

88. Wildanger D, Medda R, Kastrup L, Hell SW. A compact STED microscope providing 3D nanoscale resolution. J Microsc. 2009;236(1):35-43. doi:10.1111/j.1365-2818.2009.03188.x.

89. Schachtrup C, Ryu JK, Mammadzada K, Khan AS, Carlton PM, Perez A, et al. Nuclear pore complex remodeling by p75(NTR) cleavage controls TGF-beta signaling and astrocyte functions. Nat Neurosci. 2015;18(8):1077-80. doi:10.1038/nn.4054.

90. Malkusch S, Endesfelder U, Mondry J, Gelleri M, Verveer PJ, Heilemann M. Coordinate-based colocalization analysis of single-molecule localization microscopy data. Histochem Cell Biol. 2012;137(1):1-10. doi:10.1007/s00418-011-0880-5.

91. Zessin PJ, Krüger CL, Malkusch S, Endesfelder U, Heilemann M. A hydrophilic gel matrix for single-molecule super-resolution microscopy. Opt Nanoscopy. 2013;2(1):1-8.

92. French JB, Jones SA, Deng H, Pedley AM, Kim D, Chan $\mathrm{CY}$, et al. Spatial colocalization and functional link of purinosomes with mitochondria. Science. 2016;351(6274): 733-7. doi:10.1126/science.aac6054.

93. Gahlmann A, Ptacin JL, Grover G, Quirin S, von Diezmann AR, Lee MK, et al. Quantitative multicolor subdiffraction imaging of bacterial protein ultrastructures in three dimensions. Nano Lett. 2013;13(3):987-93. doi:10.1021/nl304071h.

94. Gurskaya NG, Verkhusha VV, Shcheglov AS, Staroverov DB, Chepurnykh TV, Fradkov AF, et al. Engineering of a monomeric green-to-red photoactivatable fluorescent protein induced by blue light. Nat Biotechnol. 2006;24(4):461-5. doi:10.1038/nbt1191.

95. Wilmes S, Staufenbiel M, Lisse D, Richter CP, Beutel O, Busch KB, et al. Triple-color super-resolution imaging of live cells: resolving submicroscopic receptor organization in the plasma membrane. Angew Chem Int Ed. 2012;51(20):4868-71. doi:10.1002/anie.201200853.

96. Baddeley D, Crossman D, Rossberger S, Cheyne JE, Montgomery $\mathrm{JM}$, Jayasinghe ID, et al. 4D super-resolution microscopy with conventional fluorophores and single wavelength excitation in optically thick cells and tissues. PLoS One. 2011;6(5), e20645. doi:10.1371/journal.pone.0020645.

97. Zhao T, Wang Y, Zhai Y, Qu X, Cheng A, Du S, et al. A userfriendly two-color super-resolution localization microscope. Opt Express. 2015;23(2):1879-87. doi:10.1364/OE.23.001879.

98. Platonova E, Winterflood CM, Ewers H. A simple method for GFP- and RFP-based dual color single-molecule localization microscopy. ACS Chem Biol. 2015;10(6):1411-6. doi:10.1021/acschembio.5b00046. 
99. Salvador-Gallego R, Mund M, Cosentino K, Schneider J, Unsay J, Schraermeyer U, et al. Bax assembly into rings and arcs in apoptotic mitochondria is linked to membrane pores. EMBO J. 2016;35(4):389-401. doi:10.15252/embj.201593384.

100. van de Linde S, Kasper R, Heilemann M, Sauer M. Photoswitching microscopy with standard fluorophores. Appl Phys B. 2008;93(4):725-31.

101. Lukinavicius G, Umezawa K, Olivier N, Honigmann A, Yang G, Plass T, et al. A near-infrared fluorophore for live-cell super-resolution microscopy of cellular proteins. Nat Chem. 2013;5(2):1329. doi:10.1038/nchem.1546.

102. Beinlich FR, Drees C, Piehler J, Busch KB. Shuttling of PINK1 between mitochondrial microcompartments resolved by triplecolor superresolution microscopy. ACS Chem Biol. 2015;10(9): 1970-6. doi:10.1021/acschembio.5b00295.

103. Loschberger A, van de Linde S, Dabauvalle MC, Rieger B, Heilemann M, Krohne G, et al. Super-resolution imaging visualizes the eightfold symmetry of gp210 proteins around the nuclear pore complex and resolves the central channel with nanometer resolution. J Cell Sci. 2012;125(Pt 3):570-5. doi: $10.1242 /$ jes.098822.

104. Szymborska A, de Marco A, Daigle N, Cordes VC, Briggs JAG, Ellenberg J. Nuclear pore scaffold structure analyzed by superresolution microscopy and particle averaging. Science. 2013;341(6146):655-8. doi:10.1126/science.1240672.

105. Schücker K, Holm T, Franke C, Sauer M, Benavente R. Elucidation of synaptonemal complex organization by superresolution imaging with isotropic resolution. Proc Natl Acad Sci USA. 2015;112(7):2029-33. doi:10.1073/pnas.1414814112.

106. Klein T, van de Linde S, Sauer M. Live-cell super-resolution imaging goes multicolor. Chembiochem. 2012;13(13):1861-3. doi:10.1002/cbic.201200347.

107. Allen JR, Ross ST, Davidson MW. Sample preparation for single molecule localization microscopy. Phys Chem Chem Phys. 2013;15(43):18771-83. doi:10.1039/c3cp53719f.

108. Lampe A, Tadeus G, Schmoranzer J. Spectral demixing avoids registration errors and reduces noise in multicolor localizationbased super-resolution microscopy. Methods Appl Fluoresc. 2015;3(3):034006

109. Ribeiro SA, Vagnarelli P, Dong Y, Hori T, McEwen BF, Fukagawa T, et al. A super-resolution map of the vertebrate kinetochore. Proc Natl Acad Sci USA. 2010;107(23):104849. doi:10.1073/pnas.1002325107.

110. Olivier N, Keller D, Rajan VS, Gönczy P, Manley S. Simple buffers for 3D STORM microscopy. Biomedical optics express. 2013;4(6):885-99.

111. Heilemann M, van de Linde S, Mukherjee A, Sauer M. Superresolution imaging with small organic fluorophores. Angew Chem Int Ed. 2009;48(37):6903-8. doi:10.1002/anie.200902073.

112. Bates M, Dempsey GT, Chen KH, Zhuang X. Multicolor super-resolution fluorescence imaging via multi-parameter fluorophore detection. ChemPhysChem. 2012;13(1):99-107. doi:10.1002/cphc.201100735.

113. Zhang M, Chang H, Zhang Y, Yu J, Wu L, Ji W, et al. Rational design of true monomeric and bright photoactivatable fluorescent proteins. Nat Methods. 2012;9(7):727-9.

114. Paez-Segala MG, Sun MG, Shtengel G, Viswanathan S, Baird MA, Macklin JJ, et al. Fixation-resistant photoactivatable fluorescent proteins for CLEM. Nat Methods. 2015;12(3):215-8.

115. Wang S, Moffitt JR, Dempsey GT, Xie XS, Zhuang X. Characterization and development of photoactivatable fluorescent proteins for single-molecule-based superresolution imaging. Proc Natl Acad Sci USA. 2014;111(23):8452-7.

116. Adam V, Moeyaert B, David CC, Mizuno H, Lelimousin M, Dedecker $\mathrm{P}$, et al. Rational design of photoconvertible and biphotochromic fluorescent proteins for advanced microscopy applications. Chem Biol. 2011;18(10):1241-51. doi:10.1016/j.chembiol.2011.08.007.

117. Zhang X, Chen X, Zeng Z, Zhang M, Sun Y, Xi P, et al. Development of a reversibly switchable fluorescent protein for super-resolution optical fluctuation imaging (SOFI). ACS Nano. 2015;9(3):2659-67.

118. Chudakov DM, Matz MV, Lukyanov S, Lukyanov KA. Fluorescent proteins and their applications in imaging living cells and tissues. Physiol Rev. 2010;90(3):1103-63. doi:10.1152/physrev.00038.2009.

119. Patterson GH, Lippincott-Schwartz J. A photoactivatable GFP for selective photolabeling of proteins and cells. Science. 2002;297(5588):1873-7. doi:10.1126/science.1074952.

120. Andresen M, Stiel AC, Trowitzsch S, Weber G, Eggeling C, Wahl $\mathrm{MC}$, et al. Structural basis for reversible photoswitching in Dronpa. Proc Natl Acad Sci USA. 2007;104(32):13005-9. doi:10.1073/pnas.0700629104.

121. Dempsey GT, Vaughan JC, Chen KH, Bates M, Zhuang X. Evaluation of fluorophores for optimal performance in localization-based super-resolution imaging. Nat Methods. 2011;8(12):1027-36. doi:10.1038/nmeth.1768.

122. Landgraf D, Okumus B, Chien P, Baker TA, Paulsson J. Segregation of molecules at cell division reveals native protein localization. Nat Methods. 2012;9(5):480-2.

123. Wolter S, Endesfelder U, van de Linde S, Heilemann M, Sauer M. Measuring localization performance of superresolution algorithms on very active samples. Opt Express. 2011;19(8):7020-33.

124. Shannon CE. Communication in the presence of noise. P IEEE. 1949;37(1):10-21.

125. Coons $\mathrm{AH}, \mathrm{Creech} \mathrm{HJ}$, Jones RN. Immunological properties of an antibody containing a fluorescent group. Exp Biol Med. 1941;47(2):200-2. doi:10.3181/00379727-47-13084p.

126. Rothbauer U, Zolghadr K, Tillib S, Nowak D, Schermelleh L, Gahl A, et al. Targeting and tracing antigens in live cells with fluorescent nanobodies. Nat Methods. 2006;3(11):887-9.

127. Beatty KE, Liu JC, Xie F, Dieterich DC, Schuman EM, Wang Q, et al. Fluorescence visualization of newly synthesized proteins in mammalian cells. Angew Chem Int Ed. 2006;45(44):7364-7. doi:10.1002/anie.200602114.

128. Neef AB, Schultz C. Selective fluorescence labeling of lipids in living cells. Angew Chem Int Ed. 2009;48(8):1498-500. doi:10.1002/anie.200805507.

129. Salic A, Mitchison TJ. A chemical method for fast and sensitive detection of DNA synthesis in vivo. Proc Natl Acad Sci USA. 2008;105(7):2415-20. doi:10.1073/pnas.0712168105.

130. Rudkin GT, Stollar BD. High resolution detection of DNA-RNA hybrids in situ by indirect immunofluorescence. Nature. 1977;265(5593):472-3.

131. Shim SH, Xia C, Zhong G, Babcock HP, Vaughan JC, Huang B, et al. Super-resolution fluorescence imaging of organelles in live cells with photoswitchable membrane probes. Proc Natl Acad Sci USA. 2012;109(35):13978-83. doi:10.1073/pnas.1201882109.

132. Lukinavicius G, Reymond L, D'Este E, Masharina A, Gottfert F, Ta H, et al. Fluorogenic probes for live-cell imaging of the cytoskeleton. Nat Methods. 2014;11(7):731-3. doi:10.1038/nmeth.2972.

133. Lukinavicius G, Blaukopf C, Pershagen E, Schena A, Reymond L, Derivery E, et al. SiR-Hoechst is a far-red DNA stain for live-cell nanoscopy. Nat Commun. 2015;6: 8497. doi: $10.1038 /$ ncomms9497.

134. Revelo NH, Kamin D, Truckenbrodt S, Wong AB, Reuter-Jessen $\mathrm{K}$, Reisinger $\mathrm{E}$, et al. A new probe for super-resolution imaging of membranes elucidates trafficking pathways. J Cell Biol. 2014;205(4):591-606. doi:10.1083/jcb.201402066. 
135. Sun X, Zhang A, Baker B, Sun L, Howard A, Buswell J, et al. Development of SNAP-tag fluorogenic probes for wash-free fluorescence imaging. ChemBioChem. 2011;12(14):2217-26. doi:10.1002/cbic.201100173.

136. Gautier A, Juillerat A, Heinis C, Corrêa Jr IR, Kindermann M, Beaufils F, et al. An engineered protein tag for multiprotein labeling in living cells. Chem Biol. 2008;15(2):128-36. doi:10.1016/j. chembiol.2008.01.007.

137. Los GV, Encell LP, McDougall MG, Hartzell DD, Karassina N, Zimprich C, et al. HaloTag: a novel protein labeling technology for cell imaging and protein analysis. ACS Chem Biol. 2008;3(6): 373-82. doi:10.1021/cb800025k.

138. Chen Z, Jing C, Gallagher SS, Sheetz MP, Cornish VW. Secondgeneration covalent TMP-tag for live cell imaging. J Am Chem Soc. 2012;134(33):13692-9. doi:10.1021/ja303374p.

139. Dani A, Huang B, Bergan J, Dulac C, Zhuang X. Superresolution imaging of chemical synapses in the brain. Neuron. 2010;68(5): $843-56$.

140. Fritschy J-M. Is my antibody-staining specific? How to deal with pitfalls of immunohistochemistry. Eur J Neurosci. 2008;28(12): 2365-70. doi:10.1111/j.1460-9568.2008.06552.x.

141. Hinterdorfer P, Van Oijen A. Handbook of single-molecule biophysics. New York: Springer; 2009.

142. Opazo F, Levy M, Byrom M, Schafer C, Geisler C, Groemer TW, et al. Aptamers as potential tools for super-resolution microscopy. Nat Methods. 2012;9(10):938-9.

143. Paige JS, Wu KY, Jaffrey SR. RNA mimics of green fluorescent protein. Science. 2011;333(6042):642-6. doi:10.1126/science.1207339.

144. Nikić I, Kang JH, Girona GE, Aramburu IV, Lemke EA. Labeling proteins on live mammalian cells using click chemistry. Nat Protoc. 2015;10(5):780-91. doi:10.1038/nprot.2015.045.

145. Lajoie MJ, Rovner AJ, Goodman DB, Aerni H-R, Haimovich AD, Kuznetsov G, et al. Genomically recoded organisms expand biological functions. Science. 2013;342(6156):357-60. doi:10.1126/science.1241459.

146. Uttamapinant C, Howe JD, Lang K, Beránek V, Davis L, Mahesh $\mathrm{M}$, et al. Genetic code expansion enables live-cell and superresolution imaging of site-specifically labeled cellular proteins. J Am Chem Soc. 2015;137(14):4602-5. doi:10.1021/ja512838z.

147. Amann R, Fuchs BM. Single-cell identification in microbial communities by improved fluorescence in situ hybridization techniques. Nat Rev Microbiol. 2008;6(5):339-48.

148. Patel NS, Rhinn M, Semprich CI, Halley PA, Dollé P, Bickmore WA, et al. FGF signalling regulates chromatin organisation during neural differentiation via mechanisms that can be uncoupled from transcription. PLoS Genet. 2013;9(7), e1003614. doi:10.1371/journal.pgen.1003614.

149. Nora EP, Lajoie BR, Schulz EG, Giorgetti L, Okamoto I, Servant N, et al. Spatial partitioning of the regulatory landscape of the X-inactivation center. Nature. 2012;485(7398): 381-5. doi:10.1038/nature11049.

150. Doksani Y, Wu JY, de Lange T, Zhuang X. Super-resolution fluorescence imaging of telomeres reveals TRF2-dependent T-loop formation. Cell. 2013;155(2):345-56. doi:10.1016/j.cell.2013.09.048.

151. Vicidomini G, Ta H, Honigmann A, Mueller V, Clausen MP, Waithe D, et al. STED-FLCS: an advanced tool to reveal spatiotemporal heterogeneity of molecular membrane dynamics. Nano Lett. 2015;15(9):5912-8. doi:10.1021/acs.nanolett.5b02001.

152. Pan D, Hu Z, Qiu F, Huang ZL, Ma Y, Wang Y, et al. A general strategy for developing cell-permeable photo-modulatable organic fluorescent probes for live-cell super-resolution imaging. Nat Commun. 2014;5:5573. doi:10.1038/ncomms6573.

153. Taylor DL, Wang Y-L. Molecular cytochemistry: incorporation of fluorescently labeled actin into living cells. Proc Natl Acad Sci USA. 1978;75(2):857-61.
154. Neumann E, Schaefer-Ridder M, Wang Y, Hofschneider P. Gene transfer into mouse lyoma cells by electroporation in high electric fields. EMBO J. 1982;1(7):841.

155. McNeil PL, Warder E. Glass beads load macromolecules into living cells. J Cell Sci. 1987;88(5):669-78.

156. Barber K, Mala RR, Lambert MP, Qiu R, MacDonald RC, Klein WL. Delivery of membrane-impermeant fluorescent probes into living neural cell populations by lipotransfer. Neurosci Lett. 1996;207(1):17-20.

157. Bruckbauer A, James P, Zhou D, Yoon JW, Excell D, Korchev Y, et al. Nanopipette delivery of individual molecules to cellular compartments for single-molecule fluorescence tracking. Biophys J. 2007;93(9):3120-31.

158. Prasher DC, Eckenrode VK, Ward WW, Prendergast FG, Cormier MJ. Primary structure of the Aequorea victoria green-fluorescent protein. Gene. 1992;111(2):229-33.

159. Xu K, Shim S-H, Zhuang X. Super-resolution imaging through stochastic switching and localization of single molecules: an overview. In: Tinnefeld P, Eggeling C, Hell SW, editors. Far-field optical nanoscopy. Berlin: Springer; 2013. p. 27-64.

160. Heim R, Prasher DC, Tsien RY. Wavelength mutations and posttranslational autoxidation of green fluorescent protein. Proc Natl Acad Sci USA. 1994;91(26):12501-4.

161. Subach FV, Malashkevich VN, Zencheck WD, Xiao H, Filonov GS, Almo SC, et al. Photoactivation mechanism of PAmCherry based on crystal structures of the protein in the dark and fluorescent states. Proc Natl Acad Sci USA. 2009;106(50):21097-102.

162. Cormack BP, Valdivia RH, Falkow S. FACS-optimized mutants of the green fluorescent protein (GFP). Gene. 1996;173(1 Spec No):33-8.

163. Brakemann T, Stiel AC, Weber G, Andresen M, Testa I, Grotjohann T, et al. A reversibly photoswitchable GFP-like protein with fluorescence excitation decoupled from switching. Nat Biotechnol. 2011;29(10):942-7. doi:10.1038/nbt.1952.

164. Schafer SP, Dittrich PS, Petrov EP, Schwille P. Single molecule fluorescence imaging of the photoinduced conversion and bleaching behavior of the fluorescent protein Kaede. Microsc Res Tech. 2006;69(3):210-9. doi:10.1002/jemt.20283.

165. Shin YC, Bischof GF, Lauer WA, Desrosiers RC. Importance of codon usage for the temporal regulation of viral gene expression. Proc Natl Acad Sci USA. 2015;112(45):14030-5. doi:10.1073/pnas.1515387112.

166. Kishino A, Yanagida T. Force measurements by micromanipulation of a single actin filament by glass needles. Nature. 1988;334(6177):74-6.

167. Aitken CE, Marshall RA, Puglisi JD. An oxygen scavenging system for improvement of dye stability in single-molecule fluorescence experiments. Biophys J. 2008;94(5):1826-35. doi:10.1529/biophysj.107.117689.

168. Swoboda M, Henig J, Cheng HM, Brugger D, Haltrich D, Plumere N, et al. Enzymatic oxygen scavenging for photostability without $\mathrm{pH}$ drop in single-molecule experiments. ACS Nano. 2012;6(7):6364-9. doi:10.1021/nn301895c.

169. Cordes T, Strackharn M, Stahl SW, Summerer W, Steinhauer C, Forthmann C, et al. Resolving single-molecule assembled patterns with superresolution blink-microscopy. Nano Lett. 2010;10(2): 645-51. doi:10.1021/n1903730r.

170. Schäfer P, van de Linde S, Lehmann J, Sauer M, Doose S. Methylene blue- and thiol-based oxygen depletion for superresolution imaging. Anal Chem. 2013;85(6):3393-400. doi:10.1021/ac400035k.

171. Vogelsang J, Cordes T, Forthmann C, Steinhauer C, Tinnefeld P. Controlling the fluorescence of ordinary oxazine dyes for singlemolecule switching and superresolution microscopy. Proc Natl Acad Sci USA. 2009;106(20):8107-12. doi:10.1073/pnas.0811875106. 
172. Vaughan JC, Dempsey GT, Sun E, Zhuang X. Phosphine quenching of cyanine dyes as a versatile tool for fluorescence microscopy. J Am Chem Soc. 2013;135(4):1197-200. doi:10.1021/ja3105279.

173. Perkovic M, Kunz M, Endesfelder U, Bunse S, Wigge C, Yu Z, et al. Correlative light-and electron microscopy with chemical tags. J Struct Biol. 2014;186(2):205-13.

174. Cordes T, Vogelsang J, Tinnefeld P. On the mechanism of Trolox as antiblinking and antibleaching reagent. J Am Chem Soc. 2009;131(14):5018-9. doi:10.1021/ja809117z.

175. Longin A, Souchier C, Ffrench M, Bryon P. Comparison of antifading agents used in fluorescence microscopy: image analysis and laser confocal microscopy study. J Histochem Cytochem. 1993;41(12):1833-40.

176. Widengren J, Chmyrov A, Eggeling C, Lofdahl PA, Seidel CA. Strategies to improve photostabilities in ultrasensitive fluorescence spectroscopy. J Phys Chem A. 2007;111(3):429-40. doi:10.1021/jp0646325.

177. Senavirathne G, Liu J, Lopez Jr MA, Hanne J, Martin-Lopez J, Lee JB, et al. Widespread nuclease contamination in commonly used oxygen-scavenging systems. Nat Methods. 2015;12(10): 901-2. doi:10.1038/nmeth.3588.

178. Song L, Varma CA, Verhoeven JW, Tanke HJ. Influence of the triplet excited state on the photobleaching kinetics of fluorescein in microscopy. Biophys J. 1996;70(6):2959-68. doi:10.1016/S0006-3495(96)79866-1.

179. Rasnik I, McKinney SA, Ha T. Nonblinking and long-lasting single-molecule fluorescence imaging. Nat Methods. 2006;3(11): 891-3. doi:10.1038/nmeth934.

180. Chmyrov A, Sanden T, Widengren J. Iodide as a fluorescence quencher and promoter-mechanisms and possible implications. J Phys Chem B. 2010;114(34):11282-91. doi:10.1021/jp103837f.

181. Johnson E, Seiradake E, Jones EY, Davis I, Grunewald K, Kaufmann R. Correlative in-resin super-resolution and electron microscopy using standard fluorescent proteins. Sci Rep. 2016;6:22681. doi:10.1038/srep22681.

182. Valnes KR, Brandtzaeg P. Retardation of immunofluorescence fading during microscopy. J Histochem Cytochem. 1985;33(8): 755-61.

183. Tinnefeld P, Cordes T. 'Self-healing' dyes: intramolecular stabilization of organic fluorophores. Nat Methods. 2012;9(5):426-7. doi:10.1038/nmeth.1977.

184. Lukyanov KA, Chudakov DM, Lukyanov S, Verkhusha VV. Innovation: photoactivatable fluorescent proteins. Nat Rev Mol Cell Biol. 2005;6(11):885-91. doi:10.1038/nrm1741.

185. Wiedenmann J, Ivanchenko S, Oswald F, Schmitt F, Rocker C, Salih A, et al. EosFP, a fluorescent marker protein with UV-inducible greento-red fluorescence conversion. Proc Natl Acad Sci USA. 2004;101(45):15905-10. doi:10.1073/pnas.0403668101.

186. Levitus M, Ranjit S. Cyanine dyes in biophysical research: the photophysics of polymethine fluorescent dyes in biomolecular environments. Q Rev Biophys. 2011;44(1):123-51. doi: $10.1017 / \mathrm{S} 0033583510000247$.

187. Marriott G, Ottl J. Synthesis and applications of heterobifunctional photocleavable cross-linking reagents. Methods Enzymol. 1998;291:155-75.

188. Vaughan JC, Jia S, Zhuang X. Ultrabright photoactivatable fluorophores created by reductive caging. Nat Methods. 2012;9(12):1181-4. doi:10.1038/nmeth.2214.

189. Mitchison TJ, Sawin KE, Theriot JA, Gee K, Mallavarapu A. Caged fluorescent probes. Methods Enzymol. 1998;291:63-78.

190. Wysocki LM, Grimm JB, Tkachuk AN, Brown TA, Betzig E, Lavis LD. Facile and general synthesis of photoactivatable xanthene dyes. Angew Chem Int Ed. 2011;50(47):11206-9. doi:10.1002/anie.201104571.
191. Berardozzi R, Adam V, Martins A, Bourgeois D. Arginine 66 controls dark-state formation in green-to-red photoconvertible fluorescent proteins. J Am Chem Soc. 2016;138(2):558-565.

192. Lee S-H, Shin JY, Lee A, Bustamante C. Counting single photoactivatable fluorescent molecules by photoactivated localization microscopy (PALM). Proc Natl Acad Sci USA. 2012;109(43):17436-41.

193. Endesfelder U, Finan K, Holden SJ, Cook PR, Kapanidis AN, Heilemann M. Multiscale spatial organization of RNA polymerase in Escherichia coli. Biophys J. 2013;105(1): 172-81. doi:10.1016/j.bpj.2013.05.048.

194. Puchner EM, Walter JM, Kasper R, Huang B, Lim WA. Counting molecules in single organelles with superresolution microscopy allows tracking of the endosome maturation trajectory. Proc Natl Acad Sci USA. 2013;110(40):16015-20.

195. Lando D, Endesfelder U, Berger H, Subramanian L, Dunne PD, McColl J, et al. Quantitative single-molecule microscopy reveals that CENP-A(Cnp1) deposition occurs during G2 in fission yeast. Open Biol. 2012;2(7):120078. doi:10.1098/rsob.120078.

196. Durisic N, Laparra-Cuervo L, Sandoval-Álvarez Á, Borbely JS, Lakadamyali M. Single-molecule evaluation of fluorescent protein photoactivation efficiency using an in vivo nanotemplate. Nat Methods. 2014;11(2):156-62.

197. Sydor AM, Czymmek KJ, Puchner EM, Mennella V. Superresolution microscopy: from single molecules to supramolecular assemblies. Trends Cell Biol. 2015;25(12):730-48.

198. Mennella V, Keszthelyi B, McDonald KL, Chhun B, Kan F, Rogers GC, et al. Subdiffraction-resolution fluorescence microscopy reveals a domain of the centrosome critical for pericentriolar material organization. Nat Cell Biol. 2012;14(11):1159-68. doi:10.1038/ncb2597.

199. Burns S, Avena JS, Unruh JR, Yu Z, Smith SE, Slaughter BD, et al. Structured illumination with particle averaging reveals novel roles for yeast centrosome components during duplication. Elife. 2015;4, e08586.

200. Sonnen KF, Schermelleh L, Leonhardt H, Nigg EA. 3D-structured illumination microscopy provides novel insight into architecture of human centrosomes. Biol Open. 2012;1(10):965-76. doi:10.1242/bio.20122337.

201. Briggs JA. Structural biology in situ - the potential of subtomogram averaging. Curr Opin Struct Biol. 2013;23(2): 261-7. doi:10.1016/j.sbi.2013.02.003.

202. Ran FA, Hsu PD, Wright J, Agarwala V, Scott DA, Zhang F. Genome engineering using the CRISPR-Cas9 system. Nat Protoc. 2013;8(11):2281-308.

203. Berning S, Willig KI, Steffens H, Dibaj P, Hell SW. Nanoscopy in a living mouse brain. Science. 2012;335(6068):551. doi:10.1126/science.1215369.

204. Maglione M, Sigrist SJ. Seeing the forest tree by tree: superresolution light microscopy meets the neurosciences. Nat Neurosci. 2013;16(7):790-7.

205. Persson F, Lindén M, Unoson C, Elf J. Extracting intracellular diffusive states and transition rates from single-molecule tracking data. Nat Methods. 2013;10(3):265-9.

206. Chacko JV, Harke B, Canale C, Diaspro A. Cellular level nanomanipulation using atomic force microscope aided with superresolution imaging. J Biomed Opt. 2014;19(10):105003. doi:10.1117/1.JBO.19.10.105003.

207. Wagner M, Weber P, Bruns T, Strauss WS, Wittig R, Schneckenburger H. Light dose is a limiting factor to maintain cell viability in fluorescence microscopy and single molecule detection. Int J Mol Sci. 2010;11(3):956-66.

208. Wäldchen S, Lehmann J, Klein T, van de Linde S, Sauer M. Lightinduced cell damage in live-cell super-resolution microscopy. Sci Rep. 2015;5:15348. 
209. Keller PJ, Schmidt AD, Santella A, Khairy K, Bao Z, Wittbrodt J, et al. Fast, high-contrast imaging of animal development with scanned light sheet-based structured-illumination microscopy. Nat Methods. 2010;7(8):637-42.

210. Gao L, Shao L, Higgins CD, Poulton JS, Peifer M, Davidson MW, et al. Noninvasive imaging beyond the diffraction limit of 3D dynamics in thickly fluorescent specimens. Cell. 2012;151(6):1370-85.

211. Ingaramo M, York AG, Wawrzusin P, Milberg O, Hong A, Weigert R, et al. Two-photon excitation improves multifocal structured illumination microscopy in thick scattering tissue. Proc Natl Acad Sci USA. 2014;111(14):5254-9.

212. Hajj B, Wisniewski J, El Beheiry M, Chen J, Revyakin A, Wu C, et al. Whole-cell, multicolor superresolution imaging using volumetric multifocus microscopy. Proc Natl Acad Sci USA. 2014;111(49):17480-5.

213. Ji N, Milkie DE, Betzig E. Adaptive optics via pupil segmentation for high-resolution imaging in biological tissues. Nat Methods. 2010;7(2):141-7.

214. Holden S, Sage D. Imaging: super-resolution fight club. Nat Photonics. 2016;10(3):152-3.

215. Endesfelder U. Advances in correlative single-molecule localization microscopy and electron microscopy. NanoBioImaging. 2014;1(1).

216. Liss V, Barlag B, Nietschke M, Hensel M. Self-labelling enzymes as universal tags for fluorescence microscopy, super-resolution microscopy and electron microscopy. Sci Rep. 2015;5:17740. 